\title{
Descending neocortical output critical for skilled forelimb movements is distributed across projection cell classes
}

Junchol Park ${ }^{1, t, *}$, James W. Phillips ${ }^{1,2, \dagger}$, Kathleen A. Martin ${ }^{1,3}$, Adam W. Hantman ${ }^{1}$, and Joshua T. Dudman ${ }^{1, *}$

\footnotetext{
${ }^{1}$ Janelia Research Campus, Howard Hughes Medical Institute, Ashburn, VA 20147

${ }^{2}$ Department of Physiology, Development and Neuroscience, University of Cambridge, UK

${ }^{3}$ current address: Center for Neural Science, New York University, New York, NY, USA

* correspondence: parkj@janelia.hhmi.org, dudmanj@janelia.hhmi.org

${ }^{\dagger}$ co-first authors
}

\begin{abstract}
Motor cortex is a key node in the forebrain circuits that enable flexible control of limb movements. The influence of motor cortex on movement execution is primarily carried by either pyramidal tract (PT) neurons, which project directly to the midbrain, brainstem and spinal cord, or intratelencephalic (IT) neurons, which project within the forebrain. The logic of the interplay between these cell types and their relative contribution to the control of forelimb movements remains unclear. Here we combine large-scale neural recordings across all layers of motor cortex with cell-type specific perturbations in a cortex-dependent mouse behavior: kinematically-variable manipulation of a joystick. Our data demonstrate that descending neocortical motor commands are distributed across projection cell classes with partially dissociable functions. Neural recordings revealed IT neuron activity carries a larger fraction of information about gross movement kinematics than is apparent in PT neurons. Optogenetic silencing of Layer 5 PT neurons during movement execution produced small reductions in amplitude and changes in movement trajectory. In contrast, optogenetic silencing of Layer 5 IT projection neurons produced dramatic reductions in movement amplitude. Dorsal striatum is the unique extracortical integration point for IT and PT output pathways and its activity was more dependent upon IT input than PT input during movement execution; consistent with a role of striatum in regulating movement vigor. Thus, these data suggest that the corticostriatal output pathway of IT neurons may be primarily responsible for determining the amplitude and PT output projections are more critical for determining the trajectory and/or coordination of skilled forelimb movements.
\end{abstract}

\section{Introduction}

Cortical control of movement in vertebrates stems from two major classes of output pathways that arise from pyramidal and intratelencephalic tract neurons (Bakken et al., 2020). Individual pyramidal tract (PT) neurons project directly to brainstem and spinal cord, along with many other descending systems (Kuypers, 2011; Lemon, 2008;

Muñoz-Castaneda et al., 2020; Winnubst et al., 2019). The other major class of motor 
cortical output projection are the intratelencephalic (IT) or corticostriatal projection neurons of layer 5 and layer 2/3 (Dudman and Gerfen, 2015; Muñoz-Castaneda et al., 2020; Shepherd, 2013; Turner and DeLong, 2000; Winnubst et al., 2019). The two major targets of the IT pathway are the cortex itself and the striatum of both hemispheres. Expansion and diversification of IT neuron populations appears to be a major contributor to changes in motor cortical cell types in the mammalian lineage (Bakken et al., 2020).

Due to their proximity to spinal motor neurons, PT neurons have generally been argued to be the primary source of descending forebrain motor commands (Isomura et al., 2009; Lemon, 2008; Li et al., 2015; Miri et al., 2017). However, many studies have observed substantial movement execution related activity in non-PT cell types in motor cortex (Chen et al., 2015; Huber et al., 2012; Isa et al., 2013; Lemon, 2019; Peters et al., 2017, 2014; Turner and DeLong, 2000). Subcortical structures have generally been argued to contribute to multiple aspects of movement such as locomotion (reticular pathways that modulate central pattern generators (Kiehn and Dougherty, 2016)), or orienting and escape movements (modulation of descending circuits from tectum (Branco and Redgrave, 2020; Park et al., 2020; Swanson, 2003)). To date, many studies have argued that PT neurons constitute the primary motor command output pathway whereas IT neurons are thought to be involved in other aspects of learned motor behaviors (Lemon, 2008; Li et al., 2015), but not a critical component of descending commands during execution. At the same time, IT neurons constitute the major source of cortical input to striatum (Dudman and Gerfen, 2015; Shepherd, 2013; Winnubst et al., 2019). Striatum is known to be a critical area for controlling the execution for skilled, dexterous forelimb movements (Cui et al., 2013; Desmurget and Turner, 2010; Horak and Anderson, 1984; Lemke et al., 2019; Panigrahi et al., 2015; Yttri and Dudman, 2016) and is closely associated with regulation of vigor (Dudman and Krakauer, 2016; Park et al., 2020; Turner and Desmurget, 2010). This implies a tight interplay of descending motor command signals across the IT and PT classes of projection neurons (Isomura et al., 2009) regulated by the complex microcircuitry of motor cortex (Shepherd, 2013). The logic of the interplay between these cell types and their relative contribution to descending forebrain control of skilled forelimb movements remains unclear.

Why might the neocortex have two classes of output pathway? One possibility is that they contribute to dissociable aspects of motor control; aspects that may be flexibly employed to solve specific motor control problems. For example, one may need to issue 
the same movements over a continuous range of amplitude (Mazzoni et al., 2007), utilize one or both forelimbs in a coordinated fashion (Tresilian and Stelmach, 1997), target the grasping of variable manipulanda (Vargas-Irwin et al., 2010), disinhibition or co-contraction of muscle groups (Ebbesen and Brecht, 2017), or reach out and grasp an object (Guo et al., 2015) with power or precision (Isa et al., 2013; Lemon, 2019). Partially independent aspects of control distributed across circuits could potentially allow the same motor cortical circuits more flexibility to meet these diverse control demands. Another possibility is that a lower dimensional output, perhaps the net dynamics (Shenoy et al., 2013) across the two projection systems, are critical. Largely redundant contributions across pathways could allow robustness against perturbation of a given cell type (Barrett et al., 2016).

Here we sought to assess the roles interplay between the major projection neuron cell classes in the motor cortex of mice. To address this question we used large-scale neural recording across all motor cortical lamina and striatum with cell-type specific identification and perturbation in the context of mice performing a skilled forelimb motor task. The task required mice to make uncued movements of a joystick beyond a threshold to receive a delayed reward. The threshold varied across blocks (Panigrahi et al., 2015).

Cell-type specific perturbation during movement execution revealed that inactivation of IT output dramatically reduced the amplitude of forelimb movements and disrupted task performance. In contrast, PT inactivation had a much smaller effect on movement amplitude but produced lateral deviations in movement trajectories time-locked to inactivation. Movements made during IT inactivation exhibited no such change in trajectory. This indicates that descending commands during movement execution are distributed across IT and PT cortical output pathways. Cell-type specific perturbation and simultaneous recording of motor cortex and striatum revealed that inactivation of IT output disrupted striatal encoding of movement amplitude. These data thus provide evidence that descending motor commands are distributed across two major cell-type specific output pathways with at least partially dissociable contributions to the control of forelimb movement execution.

\section{Results}

To assess how neocortical function is related to a flexible, skilled forelimb movement we used a task (Panigrahi et al., 2015; Yttri and Dudman, 2016) in which mice 
were trained to make self-initiated (uncued) movements of varying amplitude to obtain a delayed (1 s) water reward. This task allowed us to isolate forelimb movements from reward collection and also examine changes in neural activity associated with a motor command variable - scaling of movement amplitude $(9.35 \pm 1.91 \mathrm{~mm}$, range: 3.49-29.26 $\mathrm{mm}$ ). Briefly, in the variable amplitude operant (VAO) task head-fixed mice had to move a joystick past a threshold of varying amplitude across three blocks to obtain a delayed water reward (Figure 1a-b, Video 1). After several weeks of training, mice were able to adjust reach amplitude across blocks to efficiently collect rewards (Figure 1c, repeated measures ANOVA, $F_{2,10}=8.94, p=0.006$, pairwise test between blocks with tukey-kramer correction, $p$ $<0.05 ; \mathrm{n}=6$ mice).

We first asked whether activity in the forelimb motor cortex (MCtx ${ }^{\mathrm{FL}}$ ) was critical for performance of the VAO task by using optogenetic inactivation during movement execution. First, we allowed the initiation of movement to occur and then rapidly triggered (Panigrahi et al., 2015) optical inactivation of MCtx ${ }^{\mathrm{FL}}$ using VGAT-ChR2 mouse (Zhao et al., 2011). As in other mouse forelimb operant tasks, e.g. joystick (Bollu et al., 2019) or reach-to-grasp (Guo et al., 2015; Subramaniam et al., 2018), we found that MCtx ${ }^{\mathrm{FL}}$ was critical for execution of a normal amplitude and speed movement (Figure 1d-e, Video 1; ANOVA, amplitude; $F_{1,4}=10.89, p=0.029 ;$ speed; $F_{1,4}=23.96, p=0.008 ; n=3$ mice). In addition, tonic inactivation of $\mathrm{MCtx}{ }^{\mathrm{FL}}$ around the end of inter-trial intervals (ITI) (when reaches are most likely to commence) significantly reduced the probability of reach initiation (Figure 1f, ANOVA, $\mathrm{F}_{1,4}=8.38, \mathrm{p}=0.031$; $\mathrm{n}=3$ mice). Finally, optogenetic activation of layer $5 \mathrm{MCtx}^{\mathrm{FL}}$ output pathways (using the Rbp4-cre mouse line which includes the vast majority of the PT projection pathways (Muñoz-Castaneda et al., 2020)) was sufficient to invigorate movements (Figure 1-figure supplement 1). Thus, these data provide causal evidence that $\mathrm{MCtx}{ }^{\mathrm{FL}}$ activity modulates the vigor with which forelimb movements are executed in mice, similar to stimulation of motor cortex in primates (Lemon et al., 1995).

\section{Movement-related neural activity is broadly distributed}

To examine neural activity across all layers of MCtx ${ }^{\mathrm{FL}}$ during forelimb movements we used Neuropixels probes (Jun et al., 2017). We recorded neuronal activity (224 \pm 17 units per session, total 10 recording sessions) across all layers of forelimb motor cortex, dorsal and ventral striatum (Figure 1g). A total of 2241 well-isolated and histologically-verified (see 
Methods) single units were recorded across $\mathrm{MCtx}^{\mathrm{FL}}(\mathrm{N}=1102)$ and underlying striatum (STR, $\mathrm{N}=1139$ units, Figure 1-figure supplement 2 \& 3). Task-related activity was distributed across the entire recording depths including many single units in $\mathrm{MCtx}{ }^{\mathrm{FL}}$ and dorsal STR (dSTR) with robust movement-timed activity (Figure 1h-i, Figure 1-figure supplement 4a). The interval (1 s) between crossing of movement threshold and reward delivery revealed clear reward/consummatory period correlates in ventral striatum as expected, but also revealed a substantial number of units in $\mathrm{MCtx}{ }^{\mathrm{FL}}$ primarily modulated around the time of reward collection (Figure 1i, Figure 1-figure supplement 4a). Activity in a substantial fraction of MCtx ${ }^{\mathrm{FL}}$ units correlated with movement kinematics (Figure $1 \mathrm{~h}$ ).

The activity of a population of neurons can be viewed as a trajectory in a high dimensional space where every moment in time in the trajectory reflects the instantaneous firing rate of each neuron in the population (Figure 1j) (Cunningham and Yu, 2014). The activity of $\mathrm{MCtx}{ }^{\mathrm{FL}}$ or striatal neurons projected onto the first 3 principal components (PCs) reveals population trajectories that largely varied along one dimension during execution of forelimb movements and an orthogonal dimension during reward delivery and consumption (Figure 1-figure supplement $4 b-d$, figure supplement $5 a-c$ ). This indicates that at least partially separable ensembles of neurons are active during forelimb movements and reward collection - made apparent due by the largely independent timing of forelimb movements and consumptive licking in the VAO task (Figure 1b). To examine population activity related specifically to the kinematics of forelimb movements we used a targeted dimensionality reduction (Mante et al., 2013) with cross validation (see Methods). Using this method we found an axis along which the variance of neural activity was best explained by variance in forelimb movement kinematics (KN dimension; Figure 1j). By projecting MCtx ${ }^{\mathrm{FL}}$ population activity onto the KN dimension we found that single trial, cross-validated population activity scaled with reach amplitude (Figure 1k, Figure 1-figure supplement 6; ANOVA, $F_{2,27}=31.82, p=7.94 \times 10^{-8}$ ) indicating that $\mathrm{MCtx} \mathrm{FL}^{\mathrm{FL}}$ neural activity in rodents is tuned to continuous kinematic parameters of movement execution analogous to many previous reports in primate MCtx (Moran and Schwartz, 1999).

\section{Inhomogeneous laminar distribution of movement-timed activity in MCtx ${ }^{\mathrm{FL}}$}


We next sought to examine how activity related to movement execution was distributed across the cell-types and output pathways of MCtx. Regressing trial by trial activity of individual units with the movement kinematics revealed significantly correlated units distributed relatively homogeneously throughout MCtx and dSTR (Figure 1I). However, when we examined the time at which modulation of activity was maximal the peak timing of task-related activity was not distributed homogeneously (Figure 1i, m, Figure 1-figure supplement 4a). For example, reward-timed activity was dominant in units recorded from ventral STR (Figure 1i, Figure 1-figure supplement 4a). Within MCtx ${ }^{\mathrm{FL}}$ we observed a shift in the time of peak modulation of activity from movement-timed in superficial layers and upper layer 5 to around reward delivery in deeper layer 5 and layer 6 (Figure 1i, m). This analysis suggests that the inhomogeneous distribution of peak timing of task-related activity could correspond to distinct projection cell classes. Specifically, the laminar pattern of IT neurons being distributed from the pia to upper layer 5, PT neurons primarily within deep layer 5, and corticothalamic neurons found in the layer 6 (Muñoz-Castaneda et al., 2020) suggests that movement-timed activity could be more prominent in IT-type neurons.

We found many units in superficial layer 5 with clear movement-timed modulation of activity. Simultaneously recorded neurons found in deeper layer 5 often exhibited strong modulation around the time of reward collection. This characteristic pattern of activity positive modulation of activity around forelimb movement or negative modulation around forelimb movement and positive modulation around reward collection - was the dominant feature of population activity as revealed by examination of the leading PCs (total variance explained by first 3 PCs: $47 \pm 2.3 \%$; Figure 2b, Figure 1-figure supplement 4b-d). We describe these PCs as 'move+' and 'move-'. We next examined how individual neurons contributed to each PC axis as a function of an estimate of its depth relative to the cortical surface (Figure 2c). Consistent with the characterization of individual unit activity previously (Figure $1 \mathrm{~m}$, $2 \mathrm{a}-\mathrm{c}$ ), the move+ and move- PCs had a distinct laminar distribution (Figure 2d; two-way ANOVA, $F_{1,29}=2.15, p=4.0 \times 10^{-4}$, bin-by-bin test, $\left.p<0.05\right)$. This indicates that MCtx ${ }^{F L}$ population activity that tends to be less active during movement execution and increased during reward collection primarily arises around deep layer 5 . In contrast, the large positive modulation of activity during forelimb movement execution that is correlated with kinematics primarily comes from more superficial layers. 
Previous work has primarily focused on an analysis of differences in the mean activity per cell-type (Economo et al., 2018; Li et al., 2015; Peters et al., 2014). However, mean activity during movement could reflect a common modulation (e.g. movement initiation), as opposed to motor commands that are expected to correlate with kinematics (Shenoy et al., 2013). The variable amplitude of forelimb movements in the joystick task provides rich trial by trial variation in kinematics with which to assess motor correlates. To assess whether the identified neural populations in our electrophysiological data were consistent with descending commands that instruct movement we trained decoders of movement amplitude (see Methods). An example of the performance of one such decoder for 20 concatenated forelimb movement epochs reveals that the amplitude and time course of movement could be captured across diverse kinematic profiles (Figure 2e). Note that the decoder could accurately predict both the amplitude and direction (e.g. change in sign of $X$ position) of movements. As with our analysis of population activity timing, we also found that the laminar distribution of units that contributed to movement decoding was inhomogeneous (Figure 2f). We found that many units localized to layer 5 contributed to the decoding of movement kinematics consistent with the large enhancement of movement amplitude during activation of layer 5 projection neurons (Figure 1-figure supplement 1). However, as with previous analyses of peak timing of activity we again observed relatively little contribution of neurons in deep layer 5 (Figure 2f). This decoding analysis thus suggests that the primary source of cortical motor commands may arise from cell-types localized to more superficial positions including upper layer 5.

\section{Prevalence of motor command-like activity in IT neurons}

While distant laminar positions can reasonably be used to distinguish putative cell-class identity of recorded neurons (e.g. layer 3 vs layer 6), there is substantial overlap in laminar position for several critical cell types. Notably individual layer 5a IT and layer 5b PT neuron classes can be overlapping in their laminar positions (Hooks et al., 2011; Muñoz-Castaneda et al., 2020; Winnubst et al., 2019). Our optogenetic activation experiments indicated that these layer 5 pathways were sufficient to modulate forelimb movement kinematics, and decoding analysis suggested that units in layer 5 carry substantial information about movement kinematics. Thus, we next sought to use optogenetic tagging (Cohen et al., 2012; Lima et al., 2009; Li et al., 2015; Pan et al., 2013) to 
identify putative cell-type differences for the two major classes of projection cells in layer 5 - layer 5a IT and layer 5b PT neurons. While there is molecular diversity within these broad cell classes (Bakken et al., 2020), mouse lines based upon TIx3 and Sim1 (Gerfen et al., 2013) allow molecular access to the most complete supersets of layer 5 IT and PT types, respectively (Muñoz-Castaneda et al., 2020). Here we use a robust and rapid optogenetic inhibitor (Brown et al., 2018) to identify neurons in awake animals to mitigate against confounds due to extensive cortical recurrent excitation (Lima et al., 2009).

To achieve labeling of PT neurons we used a retrograde virus (rAAV2-retro (Tervo et al., 2016)) with conditional expression of the inhibitory opsin FLInChR (Brown et al., 2018) injected into the brainstem (pons) of Sim1-cre mice (Gerfen et al., 2013). This strategy resulted in strong expression of an inhibitory opsin in brainstem-projecting PT neurons located within layer 5 of MCtx ${ }^{\mathrm{FL}}$ (Figure 3a, Figure 1-figure supplement 2a-b). A total of 111 units (3 mice) were identified as 'tagged' $\left(\mathrm{PT}^{+}\right)$. Importantly, tagging was performed after completion of the task but within the same recording session. In $\mathrm{PT}^{+}$subset, activity was inhibited at short latency with half-maximal inhibition occurring within $17.48 \pm 4.66 \mathrm{~ms}$ after illumination onset (Figure 3a, c, f, Figure 3-figure supplement 1; see Methods for statistical criteria for tagging). To identify layer 5 IT neurons we used a similar retrograde labeling strategy with FLInChR injected into the dorsal striatum of Tlx3-cre (Gerfen et al., 2013; Oh et al., 2014) mice. This led to expression of FLInChR in striatum-projecting IT neurons within layer 5 of $\mathrm{MCtx}^{\mathrm{FL}}$ (Figure 1-figure supplement 2c). A total of 30 units (3 mice) were identified as 'tagged' $\left(\mathrm{IT}^{+}\right.$) with half-maximal inhibition occurring within $26.83 \pm 8.11 \mathrm{~ms}$ (Figure 3b, c, h). Further consistent with selective identification of layer 5 PT and IT type neurons, the vast majority of optotagged units were distributed at depths consistent with layer 5 (Figure 3c; depth estimates from Allen Reference Atlas).

We next compared activity of these two populations of putative, identified cell-types during task performance. Individual examples often revealed dramatic differences in the timing of activity across the two populations (Figure 3d-e). The modulation of activity in $\mathrm{PT}^{+}$ population was significantly weaker than the rest of the $\mathrm{MCtx}{ }^{\mathrm{FL}}$ populations during forelimb movement (Figure 3d, f, g, j; group $x$ time interaction; repeated measures ANOVA, $F_{1,40}=$ 10.10, $p=4.66 \times 10^{-61}$, main effect of group; ANOVA, $\left.F_{1,572}=21.54, p=4.30 \times 10^{-6}\right)$. In contrast, $\mathrm{IT}^{+}$population displayed a significantly greater activity compared to $\mathrm{PT}^{+}$(Figure $3 \mathrm{e}, \mathrm{h}, \mathrm{i}$, j; 
group $x$ time interaction; repeated measures ANOVA, $F_{1,40}=7.78, p=2.65 \times 10^{-42}$, main effect of group; ANOVA, $\mathrm{F}_{1,139}=25.29, \mathrm{p}=1.49 \times 10^{-6}$ ). Many $\mathrm{PT}^{+}$neurons exhibited suppressed activity around reach start (Figure 3f, g, Figure 3-figure supplement 1). Moreover, positive modulation of activity, when apparent in a subset of $\mathrm{PT}^{+}$neurons, tended to be delayed relative to movement initiation (Figure $3 d, j-l)$. The activity of the majority of $\mathrm{PT}^{+}$neurons (69.4\%) peaked after the reward delivery, while the majority of $\mathrm{IT}^{+}$neurons (80\%) were most active prior to it (Figure $3 \mathrm{k} ; \chi_{1}^{2}=23.77, \mathrm{p}=1.08 \times 10^{-6}$ ). Likewise, the majority of $\mathrm{PT}^{+}$neurons showed the reward to reach activity ratio greater than 1 (64\%), while the ratio was less than 1 for most IT ${ }^{+}$neurons (76.7\%) (Figure 3l; $\chi_{1}^{2}=15.77, \mathrm{p}=7.14 \times 10^{-5}$ ).

Identifying cell-types via optogenetic tagging has been an important technique that has clarified cell-type specific basis of diverse neuronal correlates; however, it is also subject to well known limitations (Lima et al., 2009; Li et al., 2015). Thus, we sought to use a complementary method to assess the cell-type specific differences in the MCtx ${ }^{\mathrm{FL}}$ neural correlates of forelimb movements. We used cell-type specific calcium imaging to more precisely target two major layer 5 neuron populations in MCtx ${ }^{\mathrm{FL}}$. Specifically, we focused on superficial layer 5 IT neurons that provide dense corticostriatal projections (Dudman and Gerfen, 2015; Hooks et al., 2018) and are localized in a region that appeared to have reliable movement-timed activity in our task (Turner and DeLong, 2000) (Figure 1i, m, Figure 2). We used a virally-driven expression of GCaMP6f in Sim1-cre and Tlx3-cre mice (Gerfen et al., 2013; Li et al., 2015) which are known to preferentially drive expression of transgenes in deep layer 5b PT neurons and superficial layer 5a IT projection neurons, respectively (Figure 4a-b; Sim1-cre: 8 mice, 19 imaging sessions, N=1576 ROIs. Tlx3-cre: 7 mice, 14 imaging sessions, N=1006 ROIs) (Chen et al., 2013; Gerfen et al., 2013; Hooks et al., 2018; Li et al., 2015).

Overall the average PT and IT activity showed prominent differences that were consistent with the electrophysiology data. IT neurons, similar to electrophysiologically recorded $\mathrm{IT}^{+}$neurons, showed greater peri-movement activation than PT neurons, while PT neurons had greater activation timed to reward collection and the intertrial interval activity (Figure 4c-d). Analogous to the electrophysiological experiments we examined trajectories of population activity in a low dimensional state space spanned by the leading PCs. The first PC provided a dimension that distinguished activity of PT and IT populations. Cells with a 
negative loading on to the first PC (PC1-) were characterized by prominent activation around movement execution and were more likely to be IT neurons. In contrast, cells with a positive loading $(\mathrm{PC} 1+)$ characterized by relatively suppressed activity during movement and more reward-timed modulation of activity were more likely to be PT neurons (Figure 4e-g, PT/IT difference on PC1: $p<5.35 \times 10^{-45}$, independent t-test).

\section{Cell-type and circuit specific performance of movement kinematic decoding}

Difference between the movement-related correlates of IT and PT neuron types was quite clear. While a robust activation was observed in the IT population, a majority of PT neurons displayed negative activity modulation during movement, suggesting a distinct functional role of this PT neuronal subset. One possibility is that PT neurons may primarily contribute to forelimb movements via a "subcortical disinhibition" that acts as a gate of motor commands (Ebbesen and Brecht, 2017). However, inactivation of motor cortex failed to cause initiation of movement even when the animal was primed to initiate movement at the end of the ITI and instead reduced movement amplitude and speed (Figure 1d-f). Moreover, optogenetic activation of PT neurons (using Rbp4-cre for targeting (Gerfen et al., 2013; Muñoz-Castaneda et al., 2020)) mice invigorated movement (Figure 1-figure supplementary 1), which suggests that subcortical disinhibition is not the dominant contribution of PT neurons to control of forelimb movement in this task. We next examined whether the subset of PT neurons with suppressed activity during movement were consistent with activity that might shape kinematics during execution. If disinhibition during execution is related to trial by trial changes in movement amplitude, then a population of $\mathrm{PT}^{+}$neurons with negative modulation of activity during movement and negative correlations with movement amplitude should be prominent in the subset of PT neurons with suppressed activity. However, we found little evidence for such a pattern (19\% of $\mathrm{PT}^{+}$units in the lower left quadrant in Figure 5a). Indeed, while $\mathrm{PT}^{+}$neurons with negative modulation during movement were apparent, they tended to have positive (Figure 5a) and weaker correlations with movement kinematics (Figure 5c, independent t-test, $\left.\mathrm{t}_{126}=3.65, \mathrm{p}=3.82 \times 10^{-4}\right)$. Note that the majority of $\mathrm{IT}^{+}$neurons displayed positive modulation of activity during movement that is positively correlated with the movement amplitude (Figure 5b). 
An additional possibility is that the PT neuron population as a whole contributes to descending motor commands to a degree that is underestimated by examining individual neurons. To evaluate this possibility we examined the contribution of tagged PT neurons (regardless of sign of activity during movement) to decoding of endpoint kinematics (Figure 2e-f). This analysis revealed that $\mathrm{PT}^{+}$neurons in $\mathrm{MCtx}{ }^{\mathrm{FL}}$ did indeed make a significant contribution to decoder performance relative to shuffled controls, however, the contribution was a relatively small component in each individual session examined (Figure $5 d$; rank sum test, $p<0.01$ for 6 sessions from 3 mice). This is consistent with the relative absence of large decoder weights in layer 5 (Figure 2f). In contrast, we found that other population subsets exhibited superior decoding performance when compared with $\mathrm{PT}^{+}$ neurons across all mice and sessions examined (Figure $5 d$; rank sum test, all indicated $p<0.01$ ). Finally, we trained a naive Bayes classifier to predict the tertile of movement amplitude from which a given trial was sampled. Cross-validation was used to train and test the classifier using non-overlapping trials and the same number of units sampled from each population subset. Again we found that the $\mathrm{PT}^{+}$population could be used to decode movement well above chance, albeit less than a matched number of $\mathrm{IT}^{+}$and other population subsets (Figure 5e).

\section{Partially dissociable effects of optogenetic inactivation of Layer 5 IT and PT neurons}

These data suggest that activity in motor cortical IT neurons distributed throughout the cortical depth in MCtx ${ }^{\mathrm{FL}}$ (Muñoz-Castaneda et al., 2020) carry information about the scaling of movement amplitude and thus allow preferential decoding of endpoint kinematics - specifically amplitude. Layer 5 PT neurons, by contrast, exhibited a more heterogeneous mix of movement-related activity profiles and provided for less accurate, although still well above chance, decoding of endpoint kinematics. We next sought to assess whether these differences in neural correlates across the two major projection cell classes were reflected in dissociable functions in the control of skilled forelimb movements. Cell-type specific inactivation is very challenging to achieve, but recent work has indicated a potent optogenetic inhibitor (FLInChR) is sufficient to substantially or even completely inactivate IT or PT MCtx ${ }^{\mathrm{FL}}$ populations (Brown et al., 2018). Analogous to the labelling strategy for expression calcium indicators, we used a viral strategy with two mouse lines 
that label a broad set (Gerfen et al., 2013; Hooks et al., 2018; Muñoz-Castaneda et al., 2020) of layer 5 IT (TIX-cre) and PT (Sim1-cre) neurons (Figure 1-figure supplement 2).

To assess the relative contribution of these pathways to the execution of skilled forelimb movements we triggered laser delivery to the earliest time point after reach initiation (Panigrahi et al., 2015) detected online for a random subset ( 25\%) of trials (Figure 6a; also as in Figure 1d-e). Suppression of activity in MCtx ${ }^{\mathrm{FL}}$ Layer 5 IT neurons had a large effect on movement kinematics (Figure $6 b-c$, paired t-test, amplitude: $t_{6}=8.13, p=1.85 \times 10^{-4}$; speed: $t_{6}=5.26, p=0.002$ ) consistent with the prevalence of motor command-like activity observed in both electrophysiological and imaging datasets. In contrast, transient optogenetic suppression of PT neuron activity had a much smaller effect on the amplitude and speed of forelimb movements (Figure $6 d$-e, paired t-test, amplitude: $t_{5}=6.55, p=0.001$; speed: $\left.\mathrm{t}_{5}=2.89, \mathrm{p}=0.034, \mathrm{n}=6\right)$. However, when compared to IT inactivation, PT inactivation had a several-fold smaller effect on amplitude (IT: $-51 \pm 7 \%$, PT: $-19 \pm 2 \%$; Mean \pm SEM percent reduction from the control trials) and speed (IT: $-67 \pm 13$, PT: $-25 \pm 13$ ). We note that this smaller effect of PT inactivation on behavior occurred despite producing a larger suppression of neuronal activity (Figure 7b, Figure 7-figure supplement 1).

While performance of this task primarily demands changes in the scaling of movement amplitude, mice were nonetheless manipulating a 2D joystick and thus we next sought to examine joystick trajectories during perturbation. We first examined trajectories of individual forelimb movement in the presence and absence of Layer 5 IT inactivation. To accomplish this analysis we focused on a subset of movement trajectories with a large enough amplitude to reliably measure trajectory. We found that there was no reliable change in trajectory in this subset of behavioral trials (Figure $6 \mathrm{f}$; paired t-test, $\mathrm{t}_{6}=-1.88$, $\mathrm{p}=0.11$ ). In contrast to movement amplitude, trajectory analyses of PT inactivation revealed a reliable change in the movement trajectory along the lateral axis that was time locked to PT inactivation (Figure 6f; paired t-test, $t_{5}=-7.26, p=7.73 \times 10^{-4}$ ). Thus, these data suggest that layer 5 IT and PT projection neuron classes make partially dissociable functional contributions to the control of skilled forelimb movements that parallel the greater correlates of movement kinematics in IT neurons. In summary, IT neurons appear to play a larger role in determining movement scaling (amplitude), whereas PT neurons appear to play a larger role in determining movement trajectory (direction).

\section{Inactivation of PT and IT neurons oppositely affect striatal activity}


Are the partially dissociable functions of IT and PT neurons revealed in downstream targets? The striatum is unique in that it is the only forebrain, extra-cortical structure that integrates both IT and PT output (Dudman and Gerfen, 2015; Shepherd, 2013). Anatomical reconstructions of single neurons indicate that Layer 5 IT neurons provide much more dense axonal innervation of striatum (per neuron) as illustrated in the example populations of complete single neuron reconstructions from the PT and IT anatomical classes (Figure 7a) (Winnubst et al., 2019). Previous work has indicated that striatum plays a critical role in determining the scaling of movement kinematics in this task (Panigrahi et al., 2015; Yttri and Dudman, 2016) and similar tasks in other species (Dudman and Krakauer, 2016; Park et al., 2020; Turner and Desmurget, 2010). Thus, we next asked whether perturbations of IT output resulted in partially dissociable changes in downstream striatal activity consistent with a preferential role of IT output in determining movement scaling.

We observed robust movement-related activity distributed throughout the dorsal striatum (Figure 1i), from which the amplitude of movement could be accurately decoded (Figure 5d-e). Thus, we next examined the effect of PT inactivation during movement execution as well as its effects on the downstream target dorsal striatum. We first compared $\mathrm{PT}^{+}$neuron population activity during control (unperturbed) movements to activity during movements paired with optogenetic inactivation. This analysis revealed a dramatic suppression of activity, much larger than the modest suppression of activity observed in the $\mathrm{PT}^{+}$population during control movements (Figure 7b, Figure 7-figure supplement $1 \mathrm{a}-\mathrm{b} ; \mathrm{ANOVA}, \mathrm{F}_{1,220}=61.72, \mathrm{p}=1.74 \times 10^{-13}$ ). In contrast, the same analysis during IT perturbation revealed a significant but, if anything, lesser extent of inactivation (Figure 7c, Figure 7-figure supplement 1c-d; ANOVA, $\left.F_{1,58}=4.22, p<0.05\right)$. Thus, it does not appear to be the case that optogenetic inactivation during movement is ineffective in PT neurons nor that smaller behavioral effects are readily attributable to a weaker or more limited optogenetic inactivation of PT neurons relative to IT neurons.

We next examined how activity in striatum was affected by PT and IT inactivation. In contrast to the similar suppression of PT and IT neurons, we found a clear dissociation in the effect of cortical inactivation on striatal activity. Optogenetic suppression of IT neuron activity during movement resulted in a corresponding decrease in striatal activity consistent with IT providing a strong source of excitatory input (Figure 7d). However, during potent optogenetic silencing of PT neurons we found that striatal units on average increased activity during movements made during PT inactivation (Figure 7d; striatal 
modulation by PT vs IT inactivation; ANOVA, $F_{1,1146}=35.49, p=3.41 \times 10^{-9}$ ). Striatum is composed of a number of cell types including both inhibitory projections neurons (MSNs) and local interneurons. Changes in MSN output are sufficient to alter forelimb movement kinematics (Yttri and Dudman, 2016). Although it is not possible in these datasets to distinguish striatal cell types based upon molecular identity, as with other brain regions these two broad classes are roughly distinguished by their baseline firing rate. PT inactivation resulted in clear increases in the activity in the subset of striatal units with low $(<10 \mathrm{~Hz})$ baseline firing rate consistent with an effect manifest in MSN projection neurons (Figure 7e; ANOVA, $F_{1,978}=31.46, p=2.65 \times 10^{-8}$ ).

It has often been proposed or assumed that striatum likely receives movement execution-related information from MCtx via PT axon collaterals (Dudman and Krakauer, 2016; Januszewski et al., 2020; Turner and DeLong, 2000; Turner and Desmurget, 2010; Yttri and Dudman, 2018). To better examine the behavioral relevance of the increase in average striatal responses during PT inactivation, we examined striatal population activity along the KN dimension (see Fig. 1j). We first identified the KN dimension that reflected the largest change in the striatal population activity correlated with movement amplitude (Figure 7f; as done above for MCtx Figure 1j-k; ANOVA, $F_{2,27}=35.56, p=2.72 \times 10^{-8}$ ). We then asked whether population activity along this dimension was altered by optogenetic inactivation of cortical input pathways. During PT inactivation there was no significant change in KN dimension activity (Figure 7g; paired t-test, $\mathrm{t}_{5}=0.37, \mathrm{p}=0.73$ ) consistent with a relatively small effect on movement amplitude (Figure $6 \mathrm{~d}$-e). In contrast, there was a significant reduction in activity along the $\mathrm{KN}$ dimension of striatal activity during IT inactivation (Figure 7h; paired t-test, $\left.\mathrm{t}_{3}=-3.26, \mathrm{p}<0.05\right)$. Thus, although dorsal striatum carries substantial information about movement kinematics, PT inputs do not appear to be the major source in this behavior.

\section{Discussion}

The central control of movement is characterized by the ability to execute movements that achieve a specific goal (say, hitting a target) with diverse trajectories and kinematics (Bernstein, 1967). For example, animals can use their forelimbs over a continuously varying range of vigor (Baraduc et al., 2013; Manohar et al., 2015; Mazzoni et al., 2007; Panigrahi et al., 2015), utilize one or both forelimbs in a coordinated fashion (Tresilian and Stelmach, 1997), targeted to variable manipulanda (Vargas-Irwin et al., 2010), 
or reach out to eccentric targets (Guo et al., 2015) while avoiding an obstacle (Scott, 2004). It has generally been proposed that extra-cortical circuits distributed across the brain make dissociable contributions to facilitate flexible control and learning (Doya, 2000; Shmuelof and Krakauer, 2011). Descending motor cortical output consists of two major, molecularly and anatomically distinct projection classes - IT and PT. It has been less clear whether dissociable contributions are made by these cortical projection systems in addition to more distributed brain-wide motor circuits.

Much work has suggested that PT projection neurons are the critical source of descending cortical signals for skilled limb movements (Lemon, 2008; Muñoz-Castaneda et al., 2020). There has been much less theorizing about the contribution of IT neuron output in the control of movement execution (Isa et al., 2013; Park et al., 2020). Here, we show that movement-related activity in the primary forelimb motor cortex is distributed across both output pathways when mice perform a kinematically-variable, skilled forelimb movement. However, the distribution was not homogeneous - the IT projection class exhibited activity that better encoded endpoint kinematics and suppression of IT neurons in layer 5 during movement execution substantially reduced movement amplitude. In contrast, activity in PT neurons more weakly encoded endpoint kinematics (primarily amplitude in this task), and suppression of PT neurons primarily produced a change in movement trajectory coupled with much smaller changes in movement amplitude. This is surprising given the common assumption that pyramidal tract pathways are a primary or even sole determinant of motor commands during movement execution (Economo et al., 2018; Miri et al., 2017), but consistent with movement execution-related activity in diverse pyramidal neurons in rodents (Isomura et al., 2009) and primates (Turner and DeLong, 2000). Suppression of IT neuron output reduced movement encoding in striatum and thus, these data are consistent with a central role for basal ganglia in the regulation of movement vigor (Lemke et al., 2019; Yttri and Dudman, 2018, 2016) and critical functions for extrapyramidal, basal ganglia recipient motor areas in regulating forelimb reaching movements in rodents (Alstermark and Isa, 2012; Azim et al., 2014; Esposito et al., 2014; Lemke et al., 2019).

Many studies of cortical encoding of movement have focused on cued movements of individual limbs along highly stereotyped movement trajectories (Lemon, 2008). Here we addressed the role of two major projection neuron subtypes in the motor cortex using a task that demands substantial rescaling of movement amplitude. Although we attempted to produce a penetrant and robust perturbation of a broad, molecularly defined set of PT 
neurons (Sim1+ and Rbp4+ (Gerfen et al., 2013; Hooks et al., 2018; Muñoz-Castaneda et al., 2020)), it is impossible to rule out a small subset that is critically important, but failed to be targeted. Nonetheless, we can say that a large class of PT neurons (Sim1+), which includes subtypes previously argued to be the primary conduits of movement commands in other tasks (Economo et al., 2018; Li et al., 2015), make lesser contribution to the control of movement amplitude than IT neurons. In contrast, these same PT populations appear to be more critical for determining forelimb movement trajectories. This may help to account for a preferential motor correlates in Sim1+ PT neurons in motor tasks that primarily differ in direction of movement but not amplitude, such as directional licking (Li et al., 2015).

The notion that MCtx population activity can be substantially perturbed in ways that directly alter movement and those that are largely inconsequential for overt movement has been long standing. Indeed, this idea is central to account for preparatory activity in primary motor areas (Churchland et al., 2010; Kaufman et al., 2014) and complex functional-tuning between individual neurons and the muscles they innervate (Griffin et al., 2015; Lemon, 2008). One formulation of this idea is movement-potent vs movement-null dimensions of population activity (Druckmann and Chklovskii, 2012; Kaufman et al., 2014; Li et al., 2016; Shenoy et al., 2013). However, to date it has been unknown how activity in defined cell-types relates to population activity broadly and to movement-potent dimensions specifically (Sussillo et al., 2015). A common assumption is that PT output activity must be aligned with a movement-potent dimension (Miri et al., 2017; Sussillo et al., 2015). However, tests of this point have been lacking because cell-type specific perturbations combined with physiological recordings have not been examined. Here we described cell-type specific perturbations of function that refine this notion indicating that IT neurons carry movement-potent activity that contributes substantially to determining scaling of movement amplitude. In contrast, our data suggest PT activity is effectively movement-null for the scaling of forelimb movement amplitude and speed. This may allow modulation of activity in PT neurons to affect dexterous movement coordination or trajectory (Lemon, 2019, 2008; Muñoz-Castaneda et al., 2020) without altering the vigor of movement execution (Park et al., 2020).

The dorsal striatum is the primary extra-cortical locus at which IT and PT neuron projections converge (Winnubst et al., 2019) and thus provides unique insight into the coordination across these output pathways. Alterations in cell-type specific integration in striatum is thought to be responsible for multiple pathological states (Shepherd, 2013). 
Here we describe the first cell-type specific perturbations of IT and PT activity together with simultaneous recording throughout all layers of MCtx and striatum as mice perform a skilled movement task. We found that IT inactivation during movement execution results in a decrease in striatal activity as expected for a monosynaptic, excitatory input. PT inactivation during movement, in contrast, did not elicit a decrease in striatal activity, but exhibited a slight increase. This increase was correlated with a small change in movement kinematics, which could be due to an opponent interplay between the direct and indirect pathways - i.e., an increase in the indirect pathway MSNs might be expected to reduce movement speed, whereas an increase in direct pathway MSN activity would be expected to increase movement speed (Yttri and Dudman, 2016). It remains to be clarified whether or how increases in striatal activity observed during PT inactivation are related to a change in trajectory heading in this task, although much previous work has demonstrated roles for striatum in directional control of other movements such as locomotion (Klaus et al., 2019).

Our observation that descending motor commands are clearly present in IT neurons and then appear to flow through dorsal striatum may help to explain the often modest effects of pyramidotomy to gross movement amplitude (Alstermark and Pettersson, 2014; Lawrence and Kuypers, 1968) (although see (Martin and Ghez, 1988)) and also help to explain how basal ganglia can be sufficient for execution of movements with highly stereotyped kinematics following cortical lesions (Dhawale et al., 2019). However, while previous work has demonstrated that striatal activity can be sufficient to alter movement kinematics in intact animals (Park et al., 2020; Yttri and Dudman, 2016), it remains unclear whether flexible scaling of movement kinematics can be achieved independent of motor cortex.

An increasing diversity of IT neuron populations is an innovation of the primate motor cortex (Bakken et al., 2020) and is thus correlated with increasing sophistication of motor skills. A characteristic feature of human motor skills is the incredibly flexible regulation of the vigor with which actions are executed (Dudman and Krakauer, 2016). Our results argue for a model in which motor cortical output is distributed across descending pathways with dissociable functions relating to control of movement direction and scaling of movement amplitude in mice. It remains to be seen whether this distribution across pathways is also a feature of other mammals. There is strong evidence that basal ganglia output also plays a role in regulating the scaling of movement kinematics in primates (Desmurget and Turner, 2010; Dudman and Krakauer, 2016; Turner et al., 2003; Turner and 
Desmurget, 2010) and IT neurons also have clear forelimb movement execution correlates in primates (Turner and DeLong, 2000). The extent to which command-like motor cortical activity flows through diverse IT output pathways in other motor tasks and whether it allows for refinement of scaling and specification of movement execution will be a critical question for future experiments (Park et al., 2020). Our data suggest that such studies may need to distinguish tasks that demand flexible control over movement direction from those that rely primarily on scaling of movement amplitude. Here we describe approaches that allow single trial decoding of variable movements and a direct assessment of the contribution of distinct projection classes. Regardless of task, these approaches will likely prove useful for increasingly precise refinement of our understanding of how dynamics distributed across distinct projection classes, and subclasses, are coordinated for flexible and precise control of movement. 


\section{REFERENCES}

Alstermark B, Isa T. 2012. Circuits for skilled reaching and grasping. Annu Rev Neurosci 35:559-578.

Alstermark B, Pettersson L-G. 2014. Skilled reaching and grasping in the rat: lacking effect of corticospinal lesion. Front Neurol 5:103.

Arenkiel BR, Peca J, Davison IG, Feliciano C, Deisseroth K, Augustine GJ, Ehlers MD, Feng G. 2007. In vivo light-induced activation of neural circuitry in transgenic mice expressing channelrhodopsin-2. Neuron 54:205-218.

Azim E, Jiang J, Alstermark B, Jessell TM. 2014. Skilled reaching relies on a V2a propriospinal internal copy circuit. Nature 508:357-363.

Bakken TE, Jorstad NL, Hu Q, Lake BB, Tian W, Kalmbach BE, Crow M, Hodge RD, Krienen FM, Sorensen SA, Eggermont J, Yao Z, Aevermann BD, Aldridge Al, Bartlett A, Bertagnolli D, Casper T, Castanon RG, Crichton K, Daigle TL, Dalley R, Dee N, Dembrow N, Diep D, Ding S-L, Dong W, Fang R, Fischer S, Goldman M, Goldy J, Graybuck LT, Herb BR, Hou X, Kancherla J, Kroll M, Lathia K, van Lew B, Li YE, Liu CS, Liu H, Mahurkar A, McMillen D, Miller JA, Moussa M, Nery JR, Orvis J, Owen S, Palmer CR, Pham T, Plongthongkum N, Poirion O, Reed NM, Rimorin C, Rivkin A, Romanow WJ, Sedeño-Cortés AE, Siletti K, Somasundaram S, Sulc J, Tieu M, Torkelson A, Tung H, Wang X, Xie F, Yanny AM, Zhang R, Ament SA, Bravo HC, Chun J, Dobin A, Gillis J, Hertzano R, Hof PR, Höllt T, Horwitz GD, Dirk Keene C, Kharchenko PV, Ko AL, Lelieveldt BP, Luo C, Mukamel EA, Preissl S, Regev A, Ren B, Scheuermann RH, Smith K, Spain WJ, White OR, Koch C, Hawrylycz M, Tasic B, Macosko EZ, McCarroll SA, Ting JT, Zeng H, Zhang K, Feng G, Ecker JR, Linnarsson S, Lein ES. 2020. Evolution of cellular diversity in primary motor cortex of human, marmoset monkey, and mouse. bioRxiv. doi:10.1101/2020.03.31.016972

Baraduc P, Thobois S, Gan J, Broussolle E, Desmurget M. 2013. A common optimization principle for motor execution in healthy subjects and parkinsonian patients. J Neurosci 33:665-677.

Barrett DG, Denève S, Machens CK. 2016. Optimal compensation for neuron loss. Elife 5. doi:10.7554/eLife.12454

Bernstein NA. 1967. The co-ordination and regulation of movements. Oxford, New York: Pergamon Press.

Bogovic JA, Hanslovsky P, Wong A, Saalfeld S. 2016. Robust registration of calcium images by learned contrast synthesis2016 IEEE 13th International Symposium on Biomedical Imaging (ISBI). pp. 1123-1126.

Bollu T, Whitehead SC, Prasad N, Walker J, Shyamkumar N, Subramaniam R, Kardon B, Cohen I, Goldberg JH. 2019. Automated home cage training of mice in a hold-still center-out reach task.J Neurophysiol 121:500-512.

Branco T, Redgrave P. 2020. The Neural Basis of Escape Behavior in Vertebrates. Annu Rev Neurosci 43:417-439.

Brown J, Behnam R, Coddington L, Tervo DGR, Martin K, Proskurin M, Kuleshova E, Park J, Phillips J, Bergs ACF, Gottschalk A, Dudman JT, Karpova AY. 2018. Expanding the Optogenetics Toolkit by Topological Inversion of Rhodopsins. Cell 175:1131-1140.e11.

Chen SX, Kim AN, Peters AJ, Komiyama T. 2015. Subtype-specific plasticity of inhibitory circuits in motor cortex during motor learning. Nat Neurosci 18:1109-1115.

Chen T-W, Wardill TJ, Sun Y, Pulver SR, Renninger SL, Baohan A, Schreiter ER, Kerr RA, Orger MB, Jayaraman V, Looger LL, Svoboda K, Kim DS. 2013. Ultrasensitive fluorescent proteins for imaging neuronal activity. Nature 499:295-300.

Churchland MM, Cunningham JP, Kaufman MT, Foster JD, Nuyujukian P, Ryu SI, Shenoy KV. 2012. Neural population dynamics during reaching. Nature 487:51-56.

Churchland MM, Cunningham JP, Kaufman MT, Ryu SI, Shenoy KV. 2010. Cortical preparatory activity: representation of movement or first cog in a dynamical machine? Neuron 68:387-400.

Cohen JY, Haesler S, Vong L, Lowell BB, Uchida N. 2012. Neuron-type-specific signals for reward and punishment in the ventral tegmental area. Nature 482:85-88.

Cui G, Jun SB, Jin X, Pham MD, Vogel SS, Lovinger DM, Costa RM. 2013. Concurrent activation of striatal direct and indirect pathways during action initiation. Nature 494:238-242.

Cunningham JP, Yu BM. 2014. Dimensionality reduction for large-scale neural recordings. Nature Neuroscience. doi:10.1038/nn.3776

Desmurget M, Turner RS. 2010. Motor sequences and the basal ganglia: kinematics, not habits. Journal of Neuroscience 30:7685-7690.

Dhawale AK, Wolff SBE, Ko R, Ölveczky BP. 2019. The basal ganglia can control learned motor sequences independently of motor cortex. bioRxiv. doi:10.1101/827261

Doya K. 2000. Complementary roles of basal ganglia and cerebellum in learning and motor control. Curr Opin Neurobiol 10:732-739.

Druckmann S, Chklovskii DB. 2012. Neuronal circuits underlying persistent representations despite time varying activity. Curr Biol 22:2095-2103.

Dudman JT, Gerfen CR. 2015. The basal ganglia. The Rat Nervous System (Fourth Edition).

Dudman JT, Krakauer JW. 2016. The basal ganglia: from motor commands to the control of vigor. Curr Opin 
Neurobiol 37:158-166.

Ebbesen CL, Brecht M. 2017. Motor cortex - to act or not to act? Nat Rev Neurosci 18:694-705.

Economo MN, Viswanathan S, Tasic B, Bas E, Winnubst J, Menon V, Graybuck LT, Nguyen TN, Smith KA, Yao Z, Wang L, Gerfen CR, Chandrashekar J, Zeng H, Looger LL, Svoboda K. 2018. Distinct descending motor cortex pathways and their roles in movement. Nature 563:79-84.

Esposito MS, Capelli P, Arber S. 2014. Brainstem nucleus MdV mediates skilled forelimb motor tasks. Nature 508:351-356.

Gerfen CR, Paletzki R, Heintz N. 2013. GENSAT BAC cre-recombinase driver lines to study the functional organization of cerebral cortical and basal ganglia circuits. Neuron 80:1368-1383.

Goldey GJ, Roumis DK, Glickfeld LL, Kerlin AM, Reid RC, Bonin V, Schafer DP, Andermann ML. 2014. Removable cranial windows for long-term imaging in awake mice. Nat Protoc 9:2515-2538.

Griffin DM, Hoffman DS, Strick PL. 2015. Corticomotoneuronal cells are "functionally tuned." Science 350:667-670.

Guo J-Z, Graves AR, Guo WW, Zheng J, Lee A, Rodríguez-González J, Li N, Macklin J, Phillips JW, Mensh BD, Branson K, Hantman AW. 2015. Cortex commands the performance of skilled movement. Elife 4:e10774.

Harrison TC, Ayling OGS, Murphy TH. 2012. Distinct cortical circuit mechanisms for complex forelimb movement and motor map topography. Neuron 74:397-409.

Hooks BM, Hires SA, Zhang YX, Huber D, Petreanu L, Svoboda K, Shepherd GM. 2011. Laminar analysis of excitatory local circuits in vibrissal motor and sensory cortical areas. PLoS Biol 9:e1000572.

Hooks BM, Papale AE, Paletzki RF, Feroze MW, Eastwood BS, Couey JJ, Winnubst J, Chandrashekar J, Gerfen CR. 2018. Topographic precision in sensory and motor corticostriatal projections varies across cell type and cortical area. Nat Commun 9:3549.

Horak FB, Anderson ME. 1984. Influence of globus pallidus on arm movements in monkeys. II. Effects of stimulation. J Neurophysiol 52:305-322.

Huber D, Gutnisky DA, Peron S, O'Connor DH, Wiegert JS, Tian L, Oertner TG, Looger LL, Svoboda K. 2012. Multiple dynamic representations in the motor cortex during sensorimotor learning. Nature 484:473-478.

Isa T, Kinoshita M, Nishimura Y. 2013. Role of Direct vs. Indirect Pathways from the Motor Cortex to Spinal Motoneurons in the Control of Hand Dexterity. Front Neurol 4:191.

Isomura Y, Harukuni R, Takekawa T, Aizawa H, Fukai T. 2009. Microcircuitry coordination of cortical motor information in self-initiation of voluntary movements. Nat Neurosci 12:1586-1593.

Januszewski M, Schubert P, Jain V, Denk W, Fee MS. 2020. An anatomical substrate of credit assignment in reinforcement learning. BioRxiv.

Jun JJ, Steinmetz NA, Siegle JH, Denman DJ, Bauza M, Barbarits B, Lee AK, Anastassiou CA, Andrei A, Aydın Ç, Barbic M, Blanche TJ, Bonin V, Couto J, Dutta B, Gratiy SL, Gutnisky DA, Häusser M, Karsh B, Ledochowitsch P, Lopez CM, Mitelut C, Musa S, Okun M, Pachitariu M, Putzeys J, Rich PD, Rossant C, Sun W-L, Svoboda K, Carandini M, Harris KD, Koch C, O'Keefe J, Harris TD. 2017. Fully integrated silicon probes for high-density recording of neural activity. Nature 551:232-236.

Kaufman MT, Churchland MM, Ryu SI, Shenoy KV. 2014. Cortical activity in the null space: permitting preparation without movement. Nat Neurosci 17:440-448.

Kiehn O, Dougherty K. 2016. Locomotion: Circuits and Physiology. Neuroscience in the 21st Century. doi:10.1007/978-1-4939-3474-4_42

Klaus A, Alves da Silva J, Costa RM. 2019. What, If, and When to Move: Basal Ganglia Circuits and Self-Paced Action Initiation. Annu Rev Neurosci 42:459-483.

Kubota SI, Takahashi K, Nishida J, Morishita Y, Ehata S, Tainaka K, Miyazono K, Ueda HR. 2017. Whole-Body Profiling of Cancer Metastasis with Single-Cell Resolution. Cell Rep 20:236-250.

Kuypers H. 2011. Anatomy of the Descending Pathways In: Terjung R, editor. Comprehensive Physiology. Hoboken, NJ, USA: John Wiley \& Sons, Inc. p. 499.

Lawrence DG, Kuypers HG. 1968. The functional organization of the motor system in the monkey. I. The effects of bilateral pyramidal lesions. Brain 91:1-14.

Lemke SM, Ramanathan DS, Guo L, Won SJ, Ganguly K. 2019. Emergent modular neural control drives coordinated motor actions. Nat Neurosci. doi:10.1038/s41593-019-0407-2

Lemon R. 2019. Recent advances in our understanding of the primate corticospinal system. F1000Res 8. doi:10.12688/f1000research.17445.1

Lemon RN. 2008. Descending pathways in motor control. Annu Rev Neurosci 31:195-218.

Lemon RN, Johansson RS, Westling G. 1995. Corticospinal control during reach, grasp, and precision lift in man. J Neurosci 15:6145-6156.

Lima SQ, Hromádka T, Znamenskiy P, Zador AM. 2009. PINP: a new method of tagging neuronal populations for identification during in vivo electrophysiological recording. PLoS One 4:e6099.

Li N, Chen T-W, Guo ZV, Gerfen CR, Svoboda K. 2015. A motor cortex circuit for motor planning and movement. Nature 519:51-56.

Li N, Daie K, Svoboda K, Druckmann S. 2016. Robust neuronal dynamics in premotor cortex during motor 
planning. Nature 532:459-464.

Liu LD, Chen S, Economo MN, Li N, Svoboda K. 2020. Accurate localization of linear probe electrodes across multiple brains. bioRxiv.

Madisen L, Mao T, Koch H, Zhuo JM, Berenyi A, Fujisawa S, Hsu YW, Garcia AJ 3rd, Gu X, Zanella S, Kidney J, Gu H, Mao Y, Hooks BM, Boyden ES, Buzsaki G, Ramirez JM, Jones AR, Svoboda K, Han X, Turner EE, Zeng H. 2012. A toolbox of Cre-dependent optogenetic transgenic mice for light-induced activation and silencing. Nat Neurosci 15:793-802.

Manohar SG, Chong TT, Apps MA, Batla A, Stamelou M, Jarman PR, Bhatia KP, Husain M. 2015. Reward Pays the Cost of Noise Reduction in Motor and Cognitive Control. Curr Biol 25:1707-1716.

Mante V, Sussillo D, Shenoy KV, Newsome WT. 2013. Context-dependent computation by recurrent dynamics in prefrontal cortex. Nature 503:78-84.

Martin JH, Ghez C. 1988. Red nucleus and motor cortex: parallel motor systems for the initiation and control of skilled movement. Behav Brain Res 28:217-223.

Mazzoni P, Hristova A, Krakauer JW. 2007. Why don't we move faster? Parkinson's disease, movement vigor, and implicit motivation.J Neurosci 27:7105-7116.

Miri A, Warriner CL, Seely JS, Elsayed GF, Cunningham JP, Churchland MM, Jessell TM. 2017. Behaviorally Selective Engagement of Short-Latency Effector Pathways by Motor Cortex. Neuron 95:683-696.e11.

Moran DW, Schwartz AB. 1999. Motor cortical representation of speed and direction during reaching. J Neurophysiol 82:2676-2692.

Muñoz-Castaneda R, Zingg B, Matho KS, Wang Q. 2020. Cellular Anatomy of the Mouse Primary Motor Cortex. bioRxiv.

Oh SW, Harris JA, Ng L, Winslow B, Cain N, Mihalas S, Wang Q, Lau C, Kuan L, Henry AM, Mortrud MT, Ouellette B, Nguyen TN, Sorensen SA, Slaughterbeck CR, Wakeman W, Li Y, Feng D, Ho A, Nicholas E, Hirokawa KE, Bohn P, Joines KM, Peng H, Hawrylycz MJ, Phillips JW, Hohmann JG, Wohnoutka P, Gerfen CR, Koch C, Bernard A, Dang C, Jones AR, Zeng H. 2014. A mesoscale connectome of the mouse brain. Nature 508:207-214.

Osborne JE, Dudman JT. 2014. RIVETS: a mechanical system for in vivo and in vitro electrophysiology and imaging. PLoS One 9:e89007.

Packer AM, Russell LE, Dalgleish HWP, Häusser M. 2015. Simultaneous all-optical manipulation and recording of neural circuit activity with cellular resolution in vivo. Nat Methods 12:140-146.

Panigrahi B, Martin KA, Li Y, Graves AR, Vollmer A, Olson L, Mensh BD, Karpova AY, Dudman JT. 2015. Dopamine Is Required for the Neural Representation and Control of Movement Vigor. Cell 162:1418-1430.

Pan W-X, Brown J, Dudman JT. 2013. Neural signals of extinction in the inhibitory microcircuit of the ventral midbrain. Nat Neurosci 16:71-78.

Park J, Coddington LT, Dudman JT. 2020. Basal Ganglia Circuits for Action Specification. Annu Rev Neurosci. doi:10.1146/annurev-neuro-070918-050452

Peters AJ, Chen SX, Komiyama T. 2014. Emergence of reproducible spatiotemporal activity during motor learning. Nature 510:263-267.

Peters AJ, Lee J, Hedrick NG, O’Neil K, Komiyama T. 2017. Reorganization of corticospinal output during motor learning. Nature Neuroscience. doi:10.1038/nn.4596

Podgorski K, Ranganathan G. 2016. Brain heating induced by near-infrared lasers during multiphoton microscopy. J Neurophysiol 116:1012-1023.

Scott SH. 2004. Optimal feedback control and the neural basis of volitional motor control. Nat Rev Neurosci 5:532-546.

Shenoy KV, Sahani M, Churchland MM. 2013. Cortical control of arm movements: a dynamical systems perspective. Annu Rev Neurosci 36:337-359.

Shepherd GMG. 2013. Corticostriatal connectivity and its role in disease. Nat Rev Neurosci 14:278-291.

Shmuelof L, Krakauer JW. 2011. Are we ready for a natural history of motor learning? Neuron 72:469-476.

Subramaniam R, Kardon BM, Cohen I, Goldberg JH. 2018. Motor cortical inactivation reduces the gain of kinematic primitives in mice performing a hold-still center-out reach task. BioRxiv.

Sussillo D, Churchland MM, Kaufman MT, Shenoy KV. 2015. A neural network that finds a naturalistic solution for the production of muscle activity. Nat Neurosci 18:1025-1033.

Swanson LW. 2003. Brain architecture: Understanding the basic plan 263.

Tasic B, Yao Z, Graybuck LT, Smith KA, Nguyen TN, Bertagnolli D, Goldy J, Garren E, Economo MN, Viswanathan S, Penn O, Bakken T, Menon V, Miller J, Fong O, Hirokawa KE, Lathia K, Rimorin C, Tieu M, Larsen R, Casper T, Barkan E, Kroll M, Parry S, Shapovalova NV, Hirschstein D, Pendergraft J, Sullivan HA, Kim TK, Szafer A, Dee N, Groblewski P, Wickersham I, Cetin A, Harris JA, Levi BP, Sunkin SM, Madisen L, Daigle TL, Looger L, Bernard A, Phillips J, Lein E, Hawrylycz M, Svoboda K, Jones AR, Koch C, Zeng H. 2018. Shared and distinct transcriptomic cell types across neocortical areas. Nature 563:72-78.

Tennant KA, Adkins DL, Donlan NA, Asay AL, Thomas N, Kleim JA, Jones TA. 2011. The organization of the forelimb representation of the C57BL/ 6 mouse motor cortex as defined by intracortical microstimulation 
and cytoarchitecture. Cereb Cortex 21:865-876.

Tervo DGR, Hwang B-Y, Viswanathan S, Gaj T, Lavzin M, Ritola KD, Lindo S, Michael S, Kuleshova E, Ojala D, Huang C-C, Gerfen CR, Schiller J, Dudman JT, Hantman AW, Looger LL, Schaffer DV, Karpova AY. 2016. A Designer AAV Variant Permits Efficient Retrograde Access to Projection Neurons. Neuron 92:372-382.

Theis L, Berens P, Froudarakis E, Reimer J, Román Rosón M, Baden T, Euler T, Tolias AS, Bethge M. 2016. Benchmarking Spike Rate Inference in Population Calcium Imaging. Neuron 90:471-482.

Tresilian JR, Stelmach GE. 1997. Common organization for unimanual and bimanual reach-to-grasp tasks. Exp Brain Res 115:283-299.

Turner RS, DeLong MR. 2000. Corticostriatal activity in primary motor cortex of the macaque. J Neurosci 20:7096-7108.

Turner RS, Desmurget M. 2010. Basal ganglia contributions to motor control: a vigorous tutor. Curr Opin Neurobiol 20:704-716.

Turner RS, Desmurget M, Grethe J, Crutcher MD, Grafton ST. 2003. Motor subcircuits mediating the control of movement extent and speed. J Neurophysio/ 90:3958-3966.

Vargas-Irwin CE, Shakhnarovich G, Yadollahpour P, Mislow JMK, Black MJ, Donoghue JP. 2010. Decoding complete reach and grasp actions from local primary motor cortex populations.J Neurosci 30:9659-9669.

Winnubst J, Bas E, Ferreira TA, Wu Z, Economo MN, Edson P, Arthur BJ, Bruns C, Rokicki K, Schauder D, Olbris DJ, Murphy SD, Ackerman DG, Arshadi C, Baldwin P, Blake R, Elsayed A, Hasan M, Ramirez D, Dos Santos B, Weldon M, Zafar A, Dudman JT, Gerfen CR, Hantman AW, Korff W, Sternson SM, Spruston N, Svoboda K, Chandrashekar J. 2019. Reconstruction of 1,000 Projection Neurons Reveals New Cell Types and Organization of Long-Range Connectivity in the Mouse Brain. Cell. doi:10.1016/j.cell.2019.07.042

Yttri EA, Dudman JT. 2018. A proposed circuit computation in basal ganglia: History-dependent gain. Mov Disord.

Yttri EA, Dudman JT. 2016. Opponent and bidirectional selection of movement parameters in the basal ganglia. Nature 533:402-406.

Yu BM, Cunningham JP, Santhanam G, Ryu SI, Shenoy KV, Sahani M. 2009. Gaussian-Process Factor Analysis for Low-Dimensional Single-Trial Analysis of Neural Population Activity. Journal of Neurophysiology. doi:10.1152/jn.90941.2008

Zhao S, Ting JT, Atallah HE, Qiu L, Tan J, Gloss B, Augustine GJ, Deisseroth K, Luo M, Graybiel AM, Feng G. 2011. Cell type-specific channelrhodopsin-2 transgenic mice for optogenetic dissection of neural circuitry function. Nat Methods 8:745. 


\section{ACKNOWLEDGEMENTS}

The authors thank Brett Mensh and Jason Keller for comments on earlier drafts of the manuscript. The authors thank several members of Janelia Research Campus for assistance with experimental hardware and software. For Neuropixels recordings Brian Barbarits, Jennifer Colonell, Tim Harris, James Jun, Bill Karsh, Wei-Lung Sun, and Eric Yttri provided critical assistance in developing the recording system and associated hardware. Dohoung Kim and Dave (Liu) Liu provided assistance for preparation and analysis of light sheet microscopy data from cleared mouse brains. For imaging experiments Dan Flickinger provided key assistance in the design of the microscope. Janelia Viral Tools and Vivarium provided critical support for these experiments. A.W.H. is a Group Leader and J.T.D. is a Senior Group Leader at Janelia Research Campus of the Howard Hughes Medical Institute (HHMI). This work was supported by funding from HHMI.

\section{AUTHOR CONTRIBUTIONS}

Conception and design of experiments J.W.P.IJ.P.,A.W.H., \& J.T.D. Analysis of electrophysiological data: J.P. \& J.T.D. Data collection for behavioral experiments: J.P., J.W.P., K.A.M.; Data collection for electrophysiological experiments: J.P., J.G. Data collection for imaging experiments: J.W.P. The first draft of the paper was written by J.P. \&J.T.D.; Final version was produced with input from all authors.

\section{DATA AVAILABILITY}

The data used in this manuscript will be made available at janelia.figshare.com after publication or can be obtained via reasonable request to the authors at www.dudmanlab.org. 


\section{MATERIALS AND METHODS}

Male and female mice, typically aged 8-16 weeks at time of surgery, were used in this study. All procedures were approved by the Janelia Research Campus Institutional Animal Care and Use Committee (IACUC) and were consistent with the standards of the Association for Assessment and Accreditation of Laboratory Animal Care. Mice were water restricted (1-1.2ml water/day), and their weight and signs of health were monitored daily as in(Panigrahi et al., 2015).) Surgical methods closely followed those previously described(Osborne and Dudman, 2014; Panigrahi et al., 2015) except where indicated below.

\section{Behavior}

The variable amplitude operant task was run as described previously (Panigrahi et al., 2015) using a microcontroller based system (details can be obtained from

http://dudmanlab.org/html/resources.html). After surgery (see below), mice were given 5 days of recovery prior to beginning water restriction ( $1 \mathrm{ml}$ water/day). Following 3-5 days of initial water restriction, they underwent 10-20 days training, which simply involved exposure to the task and self-learning. Mice were head-fixed in a custom made head restraint box using the RIVETS head-fixation apparatus (Osborne and Dudman, 2014). The mouse's front paws rested on a metal bar attached to a spring-loaded joystick, which had unconstrained 2D maneuverability in the horizontal plane. Mice were trained to maneuver the joystick to certain thresholds varying across three different blocks (e.g. 4.2-5.7-4.2 $\mathrm{mm}$ ) to obtain a sweetened water reward delivered $1 \mathrm{~s}$ after each threshold crossing. Rewards were followed by a $3 \mathrm{~s}$ inter-trial interval (ITI) in which no movements would be rewarded. There were up to 150 trials (50 trials per block) in electrophysiology and 120 trials per session in imaging (some sessions were incomplete), with one water reward being available per trial. All behavioral events (forelimb movements, licks) were recorded on separate channels at 25 kHz (USB-6366; National Instruments, Austin, Texas) then downsampled offline at 1 $\mathrm{kHz}$. Forelimb movements were assessed offline to detect individual reaches based on the speed joystick movement. Time points of reach start and stop were defined as well as other kinematic properties such as duration, maximum amplitude and speed for each reach.

\section{Extracellular electrophysiological identification and recording of PT and IT neurons in awake head-fixed mice}

For cell-type specific in vivo recordings from motor cortex and striatum in mice performing the variable amplitude operant task, rAAV2-retro-CAG-Flex-FLInChR-mVenus $(3.0 \mathrm{E}+12 \mathrm{GC} / \mathrm{ml})$ was injected to the pons bilaterally (relative to lambda: $0.4 \mathrm{~mm}$ anterior, $0.4 \mathrm{~mm}$ lateral, 5.5, 5.75, $6 \mathrm{~mm}$ deep, $70 \mathrm{~nL} /$ depth) in Sim1-cre (KJ18Gsat RRID:MMRRC_037650-UCD) mice, selectively labeling a pyramidal type (PT) layer 5 population (Economo et al., 2018; Gerfen et al., 2013; Tervo et al., 2016). The same viral vector was injected to the dorsal striatum (relative to bregma: $0.5 \mathrm{~mm}$ anterior, 1.6 $\mathrm{mm}$ lateral, 2, 2.7, $3.5 \mathrm{~mm}$ deep) and cortex (site $1: 0.9$ anterior, 1.5 lateral, site 2: 0.1 anterior, 1.9 lateral, site 3: 0.1 anterior, 1.1 lateral, each site at 0.3 and $0.6 \mathrm{~mm}$ deep, $80 \mathrm{nl} / \mathrm{depth}$ ) in Tlx3-cre (PL56Gsat RRID:MMRRC_041158-UCD (Gerfen et al., 2013)) mice, selectively labeling a layer 5 IT population. Prior to recordings, a craniotomy was made over the recording sites (relative to bregra: $0.5 \mathrm{~mm}$ anterior, $\pm 1.7 \mathrm{~mm}$ lateral) at least 12 hours prior to recording under isoflurane anaesthesia. Exposed brain tissue was kept moist with phosphate-buffered saline at all times, and craniotomy sites were covered with Kwik-Sil elastomer (WPI) outside of the recording session.

For neural population recording using the Neuropixels probe (Jun et al., 2017), awake mice fully recovered from craniotomy were head-fixed in a RIVETS chamber (Osborne and Dudman, 2014). A Neuropixels probe (option 3 phase A) with 374 recording sites was briefly ( 2 minutes) dipped into the dil cell-labeling solution (ThermoFisher) to visualize probe tracks, then lowered through the craniotomy manually. After a slow, smooth descent $(0.2 \mathrm{~mm} / \mathrm{min})$, the probe sat still at the target depth for at least 5 min before initiation of recording to allow the electrodes to settle. An $\mathrm{Ag}$ wire was soldered onto the reference pad of the probe and shorted to ground. This reference wire was connected to an $\mathrm{Ag} / \mathrm{AgCl}$ wire was positioned on the skull. The craniotomy and the $\mathrm{Ag} / \mathrm{AgCl}$ wire were covered with a saline bath. Voltage signals are filtered (high-pass above $300 \mathrm{~Hz}$ ), amplified (200x gain), multiplexed and digitized $(30 \mathrm{kHz}$ ) on the base, allowing the direct transmission of noise-free digital data from the probe, and were recorded using an open-source software SpikeGLX 
(https://github.com/billkarsh/SpikeGLX). Recorded data were pre-processed using an open-source software JRCLUST (https://github.com/JaneliaSciComp/JRCLUST) to identify single- or multi units in the primary motor cortex (M1) and STR. To assay FLInChR expression and responses, a fiber (200 $\mathrm{mm}$ core, $0.39 \mathrm{NA}$, Thorlabs) coupled to a $574 \mathrm{~nm}$ laser source (Omicron) was placed to deliver light onto the craniotomy. Single laser pulses of $1 \mathrm{~s}$ duration with power measured at the tip of the fiber of $4-8 \mathrm{~mW}$ were delivered 60 times with $8 \mathrm{~s}$ intervals. Mice were at rest after task completion during tagging.

For cell-type specific recordings from motor cortex in mice performing the reach-to-grasp task, rAAV2-retro-hSyn-GtACR2-KV-eGFP $(8.5 \mathrm{E}+13 \mathrm{GC} / \mathrm{ml})$ was injected to the pons bilaterally (relative to lambda: $0.4 \mathrm{~mm}$ anterior, $0.4 \mathrm{~mm}$ lateral, 5.5, 5.75, $6 \mathrm{~mm}$ deep, $30 \mathrm{~nL} / \mathrm{depth}$ ) in Sim1-cre (KJ18Gsat) mice, selectively labeling a pyramidal type (PT) layer 5 population. The same viral vector was injected to the dorsal striatum (relative to bregma: $0.5 \mathrm{~mm}$ anterior, $1.7 \mathrm{~mm}$ lateral, 2.8, 2.6, 2.4 $\mathrm{mm}$ deep) and cortex (0.5 mm anterior, $1.7 \mathrm{~mm}$ lateral, 1.0, $0.5 \mathrm{~mm}$ deep) in the right hemisphere of Slc17a7-cre mice to selectively label a layer 5 IT population in the left hemisphere. All recordings and optical silencing were conducted in the left hemisphere contralateral to the reaching hand (right).

A unit with a significant reduction in the spike count during the laser (paired t-test, $a=0.01$ and/or at least $60 \%$ reduction relative to the baseline period) was considered to be optogenetically tagged.

\section{Cell-type specific closed-loop perturbation of M1 neuronal activity}

To examine the cell-type specific role of the deep layer 5 PT neurons in MCtx, we injected rAAV2-retro-CAG-Flex-FLInChR-mVenus(Brown et al., 2018; Tervo et al., 2016) into the pons (relative to lambda: $0.4 \mathrm{~mm}$ anterior, $0.4 \mathrm{~mm}$ lateral, 5.5, 5.75, $6 \mathrm{~mm}$ deep, $70 \mathrm{~nL} / \mathrm{depth}$ ) in three Sim1-cre (KJ18Gsat (Gerfen et al., 2013)) mice. Viruses obtained from Janelia Viral Tools (https://www.janelia.org/support-team/viral-tools). To examine the role of the IT neurons in MCtx, we bilaterally injected the same virus into the dorsal striatum (relative to bregma: $0.5 \mathrm{~mm}$ anterior, $1.6 \mathrm{~mm}$ lateral, 2, 2.7, $3.5 \mathrm{~mm}$ deep, $150 \mathrm{~nL} /$ depth) and cortex (site $1: 0.9$ anterior, 1.5 lateral, site 2: 0.1 anterior, 1.9 lateral, site 3: 0.1 anterior, 1.1 lateral, each site at 300+600 microns deep, 80nl/depth) in five Tlx3-cre (PL56Gsat (Gerfen et al., 2013)), respectively. In closed-loop experiments, a $500 \mathrm{~ms}$ single pulse of $574 \mathrm{~nm}$ laser was delivered bilaterally in randomly selected $30 \%$ of the trials immediately when mice moved the joystick by $1.5 \mathrm{~mm}$ from the zero point taken at the end of each ITI.

To examine the general role of MCtx in control of forelimb movement regardless of the projection neuronal cell-type, we implanted optical fibers (200 mm core, 0.39 NA, Thorlabs) bilaterally to place fiber tips right onto the pia of the brain in VGAT-ChR2-eYFP (Arenkiel et al., 2007) (Figure 1d-f) or Rbp4-cre RRID:MMRRC_037128-UCD (Gerfen et al., 2013)::Ai32 RRID:IMSR_JAX:024109(Madisen et al., 2012) (Figure 1-figure supplement 1) mice. In closed-loop experiments, a $500 \mathrm{~ms}$ single pulse of $473 \mathrm{~nm}$ laser was delivered in randomly selected trials triggered by a slight joystick movement caused by mice. In open-loop experiments, a 3 s single pulse of $473 \mathrm{~nm}$ laser was delivered in randomly selected $30 \%$ of trials at a given time point ( $2 \mathrm{~s}$ after previous reward delivery during inter-trial interval in select trials) regardless of animals' behavior.

\section{Cell-type specific two-photon calcium imaging}

Viruses were AAV 2/1-Flex-GCaMP6f, diluted to $2 * 10^{12} \mathrm{gc} / \mathrm{ml}$ (Chen et al., 2013) RRID:Addgene_58514 and obtained from Janelia Viral Tools (https://www.janelia.org/support-team/viral-tools). 5 injections performed in a cross-shape, centered on 1.6 lateral, 0.6 rostral. $20 \mathrm{~nL}$ was ejected at $600 \mathrm{um}$ depth. This center was chosen based upon previous microstimulation work(Harrison et al., 2012; Tennant et al., 2011). Imaging was restricted to one month after injection to minimise overexpression.

$3 \mathrm{~mm}$-wide circular imaging windows were made over the left cortical hemisphere in all animals, following the method of Goldey et al (Goldey et al., 2014). Window implants were centered on the virus injection center, and fixed in place using cyanoacrylate glue and dental acrylic. Windows (custom ordered from Potomac photonics) were made by placing three windows together, with the top window being $3.5 \mathrm{~mm}$, the bottom two being $3 \mathrm{~mm}$, such that the top window rested on thinned skull area. This triple window arrangement was used to increase downward pressure on the brain 
and stabilize the brain motion.

Imaging was performed with a custom built two photon laser scanning microscope running scanlmage software (latest versions, from 2013-2016; https://vidriotechnologies.com). GCaMP6f was excited with a ti:sapphire laser, tuned to $920 \mathrm{~nm}$. Imaging was typically performed at $33 \mathrm{~Hz}$ via bidirectional scanning with a resonant galvo. Power at sample did not exceed $150 \mathrm{~mW}$. In poorer quality windows, frame rate was halved to allow an increase in peak pulse power. This was done to minimise photodamage from thermal effects (Podgorski and Ranganathan, 2016). Depth of recording ranged from 350um-450um, depending upon imaging clarity, corresponding to the proximal dendritic region of the apical dendrite.

All imaging data analysis was performed in Python using custom-written scripts unless otherwise stated. Imaging data was motion corrected in two stages. Firstly, an image average was taken for a session across all frames. Secondly, each frame was then motion registered to that image, based upon a Fourier-based cross-correlation approach to detect the optimal corrective displacement. The average was then re-taken, and the process repeated 3 times. The result of this image registration process was examined by eye for each session to check for errors.

Region of interest (ROI) extraction was done manually in image software. ROls with high baseline fluorescence, a putative marker for unhealthy cells, were not used(Packer et al., 2015). Fluorescence traces were deconvolved to inferred rates using published code(Theis et al., 2016). We note that this is not an attempt to claim specific firing rates of neurons, but rather to reduce the distorting effect of the calcium sensors' slow kinetics on the inferred activity. We did not attempt to calibrate these inferred spike rates with real rates.

\section{Histology \\ Fluorescence light sheet microscopy of cleared mouse brain}

At completion of all electrophygiological experiments, mice were perfused with $40 \mathrm{ml}$ of cold PBS ( $\mathrm{pH} 7.4$ ) containing $20 \mathrm{U} / \mathrm{ml}$ heparin at $\sim 10 \mathrm{ml} / \mathrm{min}$, and fixed with cold $4 \%$ PFA. Extracted brains were further fixed for $24 \mathrm{hrs}$ in $4 \%$ PFA. Fixed brains were delipidated using the CUBIC-L cocktail 10 w\%/10w\% N-butyldiethanolamine/Triton X-100 for a week. Delipidated brains underwent nuclear counterstaining with TO-PRO-3 (ThermoFisher) for a day. We then transparentized the delipidated brains in the refractive index (RI) matching cocktail CUBIC-R composed of $45 \mathrm{w} \% / 30 \mathrm{w} \%$ antipyrine/nicotinamide for two days(Kubota et al., 2017). Finally, cleared brains were imaged using fluorescence light sheet microscopy (Zeiss Lightsheet Z.1) to visualize expression of FLInChR (509 $\mathrm{nm})$, probe tracks $(570 \mathrm{~nm})$, and nuclear counterstaining $(661 \mathrm{~nm})$.

The imaged 3D brain volumes (V3D) were aligned to a standardized brain coordinate system (Allen Anatomical Template, AAT) using a semi-manual landmark-based method (big warp)(Bogovic et al., 2016). The v3Ds were additionally aligned to the template MRI image volume (MRI3D) acquired using fixed brains in the skull to further correct for any distortion due to extraction of the brain from the skull (Liu et al., 2020). Each probe track was manually marked on v3D fused with AAT, and the 3D coordinates of all electrode sites were finally determined on MRI3D using the mapping between AAT and MRI3D combined with the geometry of the Neuropixels probe. Using the 3D coordinates, each electrode site was labeled as a brain region according to AAT segmented into brain regions (Allen Reference Atlas, ARA). All cortical cells in our analyses were recorded from electrode sites verified to be in a motor cortical region. All cells recorded from electrodes located at the pial depth of $1.75 \mathrm{~mm}$ or upper (estimated by the manipulator) were assigned a motor cortical region. This depth of 1.75 $\mathrm{mm}$ agreed with our physiological estimation of the cortical border (Figure 1-figure supplement 3), thus, we considered $1.75 \mathrm{~mm}$ as the putative cortical border.

\section{DATA ANALYSIS METHODS Neural data analysis}

Single unit data analyses and statistical tests were performed using custom-written codes in Matlab. Spikes of isolated single units in M1 and striatal areas were counted within 1-ms bins to generate the trial-by-bin spike count matrix per unit aligned to reach start or reward delivery. The trial-averaged firing rates were calculated within 50 -ms bins and z-score normalized using the mean and standard deviation of its baseline (a 2500-ms period before reach start) firing rate. 


\section{Dimensionality reduction (PCA)}

To find the direction along which the neural population activity most covaried during task performance and extract low dimensional neural population trajectories along these directions, PCA was performed on a data matrix $D$ of size $(b \times t, n)$, where $b$ and $t$ are the number of 50 -ms time bins and the number of trials, respectively, $n$ is the number of neurons. The trial-by-trial binned spike counts are square-root transformed to construct D(Yu et al., 2009). Applying PCA to D obtains X and $W$ such that $X=D W$, where $X$ is the projection of the data onto the principal components (PCS), which are orthonormal columns comprising $W$ that contains the weights from neurons to PCs. To reveal the time-evolving patterns of population activity, $D_{t, b}$ were projected onto top three PCs, trial-averaged and strung together across time to generate neural population trajectories on each PC dimension versus time (Figure 2 b, Figure 1 -figure supplement $4 \& 5$ ).

\section{Targeted dimensionality reduction}

To quantify representation of reach amplitude by the MCtx neural population we used a targeted dimensionality reduction (Mante et al., 2013) method. The goal was to identify the dimension (axis) within the state space of length $N_{\text {unit }}$ defined by the activity of each unit, which account for neural response variance related to movement kinematic variables such as reach amplitude, speed, and the number of licking.

The analysis comprised three steps. First, we conducted PCA to denoise the population responses and focus our analyses on the subspace spanned by the first ten PCs (Churchland et al., 2012; Yu et al., 2009). A data matrix X of size $(c \times t, n)$ comprised averaged population responses corresponding to tertiles of three relevant movement kinematic variables - reach amplitude, speed, and lick count, where $\mathrm{c}$ and $\mathrm{t}$ were all possible 27 combinations of the three movement kinematic variable tertiles and the number of 50 -ms time bins, respectively, $\mathrm{n}$ was the number of neurons. The PCs of this data matrix are vectors $v_{a}$ of length $N_{\text {unit }}$, and the denoising matrix D was built using the first ten PCs, where $D=\sum_{a=1}^{10} v_{a} v_{a}^{T}$ (see the denoised regression vectors defined below).

We used a multiple linear regression to quantify how much the activity of each unit varied as a function of movement kinematic variables: $r_{i, t}(k)=\beta_{i, t}(1)$ amplitude $(k)+\beta_{i, t}(2)$ speed $(k)+\beta_{i, t}(3)$ lick $(k)+\beta_{i, t}(4),($ eq. 1$)$, where $r_{i, t}(k)$ is the z-scored response of unit $i$ at time $t$ on trial $k, \operatorname{amplitude}(k), \operatorname{speed}(k), \operatorname{lick}(k)$ are the maximum reach amplitude, reach speed, and the number of licking on trial $k$ discretized as tertiles of all trials in each behavioral session, e.g. for amplitude( $k), 1,2,3$ were assigned to trials of low, medium, high reach amplitudes. The last regression coefficient captures variance that is independent of the movement kinematic variables. The regression coefficients $\beta_{i, t}(v)$ indicate how much the trial-by-trial firing rate of unit $i$ at a given time $t$ during the trial, can be regressed onto each movement kinematic variable $v$. To estimate the regression coefficients $\beta_{i, t}(v)$, a design matrix $F_{i}$ of size $N_{\text {coef }} \times N_{\text {trial }}$ comprising values for each movement kinematic regressor across trials was built for each recorded unit $i$. The regression coefficients were then estimated as: $\beta_{i, t}=\left(F_{i} F_{i}^{T}\right)^{-1} F_{i} r_{i, t}$.

We use the regression coefficients $\beta_{i, t}$ estimated for individual units to identify dimensions within state space along which the neural population activity most covaried with movement kinematic variables. For each task variable, a 'regression vector' $\beta_{v, t}$ of length $N_{\text {unit }}$ is obtained whose entries $\beta_{v, t}(i)$ correspond to regression coefficients for kinematic variable $v$, time $t$, and unit $i$. Regression coefficient vectors $\beta_{v, t}(i)$ are then denoised by projecting them into the subspace spanned by the first ten PCs using the denoising matrix $D$ defined above:

$\beta_{v, t}^{p c a}=D \beta_{v, t}$,

Time-independent denoised regression vectors $\beta_{v}^{\max }$ are then obtained by identifying the time at which the denoised regression vectors have maximum norm. 
$\beta_{v}^{\max }=\beta_{v, t_{v}^{\max }}^{p c a}$ with
$t_{v}^{\max }=\operatorname{argmax}_{t}\left\|\beta_{v, t}^{p c a}\right\|$,

Finally, we obtain orthogonal axes in state space corresponding to neural variance associated with movement kinematic variables by orthogonalizing $\beta_{v}^{\max }$ with QR decomposition:

$$
B^{\max }=Q R,
$$

where $B^{\max }=\left[\beta_{\text {amplitude }}^{\max } \beta_{\text {speed }}^{\max } \beta_{\text {lick }}^{\max }\right]$ is a matrix whose columns are the time-independent denoised regression vectors $\beta_{v}^{\max }$. The first three columns of $Q$ correspond to the orthogonalized regression vectors $\beta_{v}^{\perp}$ which we refer to as the movement kinematic axes, $\mathrm{KN}^{\text {dim. }}, \mathrm{R}^{\text {speed }}$, and $\mathrm{R}^{\text {lick }}$ of length $N_{\text {unit }}$. Projection onto these axes reveal neural population activity as a function of movement kinematics (Figures 1j-k, 7f-h).

To focus on the neural population variance as a function of reach amplitude avoiding the issue of multicollinearity between movement kinematic variables in the linear regression model, we repeated targeted dimensionality reduction with only replacing eq. 1 with eq. 2 below with the rest of the analysis kept identical:

$r_{i, t}(k)=\beta_{i, t}(1)$ amplitude $(k)+\beta_{i, t}(2)$, (eq. 2$)$.

Targeted dimensionality reduction using the two regression models identified almost identical axes as $\mathrm{KN}^{\text {dimension, }}$, and thus the projection scores appeared to be similar. Figures represent the result using eq. 2.

Two-fold cross-validation was used; i.e., data from half of randomly selected trials were used to define $\mathrm{KN}^{\text {dimension }}$, and the data of the held out trials were projected to the $\mathrm{KN}^{\text {dimension }}$. Consistent trajectories were observed across many iterations (Figure 1-figure supplement 6), indicating that there existed a stable dimension that captures covariance of neural population activity as a function of forelimb movement kinematics.

\section{Linear (consensus) decoder}

To assess the contribution of distinct neural populations to forelimb movement, we used a linear decoder to estimate the joystick movement based on the neural activity. The decoded estimates were then correlated with the actual joystick trajectories. The decoder defines linear mapping $\left(W_{\text {decode }}\right)$ between the neural population activity and the two dimensional position of the joystick: $K=F^{T} \cdot W_{\text {decode }}$ where $F$ is the data matrix comprising the population vector of spike counts with the dimension of the number of units concatenated across all time bins and trials in the training data set. The matrix $K$ comprises two vectors each corresponding to the estimated $X$ and $Y$ amplitudes of the joystick movement. We solve for $W_{\text {decode }}$ as $W_{\text {decode }}=\left(F^{T} F\right)^{-1} F^{T} K$. For cross validation, we trained and tested the decoder using non-overlapping sets of data, i.e., different trials.

\section{Naive Bayes classifier}

To assess how informative distinct neural populations are of the executed movement amplitude, we used a Poisson naive Bayes classifier to decode which movement amplitude tertile $\left(C_{k}, k=1,2,3\right)$ a given trial is sampled from. For each of 1000 iterations, data from each subpopulation (e.g. $\mathrm{PT}^{+}, \mathrm{IT}^{\mathrm{put}}$, Striatum etc.) resampled to match the number of neurons per subpopulation are randomly split into 10 folds of trials. A Poisson likelihood function is given by the following:

$P\left(\overline{x_{t}} \mid c_{k}\right)=\prod_{i=1}^{D} \frac{\lambda_{k_{i, t}{ }_{i, t}}^{{ }^{-\lambda} k_{k, t}}}{x_{i, t} !}$,

where $\bar{x}_{t}$ is a population vector of spike counts at $t^{\text {th }}$ time bin of a trial, $k$ indicates a movement amplitude tertile. $i$ indicates neuron label, 1 to $D . \lambda_{k_{i, t}}$ is the parameter for the Poisson distribution estimated using the 9 of the 10 folds by the following: 
bioRxiv preprint doi: https://doi.org/10.1101/772517; this version posted February 22, 2021. The copyright holder for this preprint (which was not certified by peer review) is the author/funder, who has granted bioRxiv a license to display the preprint in perpetuity. It is made available under aCC-BY-NC-ND 4.0 International license.

$$
\lambda_{k_{i, t}}=\frac{1}{N_{k}} \sum_{n \in C_{k}} x_{n_{i, t}}
$$

The posterior probability of a movement amplitude tertile given the spike count vector is provided by Bayes' theorem as follows:

$P\left(c_{k} \mid \bar{x}_{t}\right)=\frac{P\left(\overline{x_{t}} \mid c_{k}\right) P\left(c_{k}\right)}{P\left(\overline{x_{t}}\right)}$

An estimated movement amplitude tertile is assigned to a given trial as follows: $\widehat{c_{k}}=\operatorname{argmax}_{k} P\left(\overline{x_{t}} \mid c_{k}\right)$

The result of naive Bayes classifier analysis is quantified as the percentage of correctly estimated test folds. 


\section{Supplemental video:}

\section{Video 1. Example trials with/without closed-loop inactivation of $\mathrm{MCtx}^{\mathrm{FL}}$ neural activity by activation of inhibitory neurons in VGAT-ChR2 mice.}

(Left) A representative trial with closed-loop inactivation of $\mathrm{MCtx}{ }^{\mathrm{FL}}$. A filled circle in the upper left corner indicates frames with laser on. Numbers in the bottom left corner indicate time relative to the laser onset triggered by slight movement of the animal. Video replay is at $x 0.2$ speed.

(Right) A representative trial without closed-loop inactivation. An empty circle in the upper left corner indicates frames for which laser would have been delivered. Numbers in the bottom left corner indicate time relative to the pseudo laser onset.

Video 1 can be found online at: https://www.dropbox.com/s/vy6dzrqwm4w1eix/Trial\%2354 139 stim-Pstim\%20\%28Conver ted\%29.mov?dl=0 


\section{Figure legends}

\section{Figure 1. Distributed task related neural dynamics in a self-initiated variable amplitude operant task}

a, Mice were trained to perform an self-initiated (uncued) variable amplitude operant task, in which movements were made for delayed reward. To perform this task, mice were head-fixed, and moved a joystick bimanually. b, Top, A representative trace of reach amplitude (i.e., distance from the 'zero' position reset at the end of each inter-trial interval) superimposed with the rasterized lick trace. Bottom, Mean normalized magnitude of joystick speed and licking aligned to reward delivery $($ time $=0$ ) and reach threshold crossing (time=-1). c, Mice adjusted their reach amplitude across the three blocks. Left plot shows data from a single session (successful trials), right plot shows the data across sessions. d-f, Brief closed-loop inactivation of MCtx ${ }^{\mathrm{FL}}$ neural activity by driving inhibitory neurons in VGAT-ChR2 mice significantly reduced ongoing reach amplitude (d) and speed (e). f, Open-loop inactivation of MCtx ${ }^{\mathrm{FL}}$ triggered around the end of ITI significantly decreased probability of reach initiation. $\mathbf{g}$, Recordings were made in $\mathrm{MCtx}{ }^{\mathrm{FL}}$ and striatum with a Neuropixels probe, which densely sampled neural activity in the depth axis spanning approximately $3.8 \mathrm{~mm}(\mathrm{n}=10$ hemispheres, $\mathrm{N}=6$ mice). $\mathbf{h}$, Many units exhibited activity correlated with movement kinematics as exemplified by the two MCtx ${ }^{\mathrm{FL}}$ units that modulated their firing rates in proportion to movement amplitude. i, Task-related neural activity was widely distributed across the depth of recordings. Mean z-score normalized activity at each depth from the pial surface. j, A schematic drawing of principal component (PC) and movement-kinematic (KN) dimensions found by dimensionality reduction within the population state space where each axis represents the activity of an individual neuron. By projecting neural population activity at every moment in time onto the KN dimension, we obtain 'neural trajectories' capturing co-modulation of neural population activity as a function of movement amplitude. $\mathbf{k}$, Cross-validated neural trajectories of movement-amplitude tertiles differed significantly along the KN dimension. I, Units whose activity significantly covaried with movement speed were distributed across all cortical layers. Each dot is a single recorded unit. Values are Pearson correlation coefficient and the corresponding $p$-value for each unit. $\mathbf{m}$, Time of peak activity shown by depth. Peak activity time was taken for each row in $\mathbf{i}$.

\section{Figure 1-figure supplement 1. Stimulation of layer 5 output neurons in MCtx ${ }^{\mathrm{FL}}$ invigorates forelimb movement}

Closed loop stimulation of the majority of descending layer 5 output neurons in MCtx $\mathrm{FL}^{\mathrm{LL}}$ labelled using the Rbp4-cre line (Gerfen et al., 2013; Tasic et al., 2018) crossed to Ai32(Madisen et al., 2012) produced increases in the amplitude (top) and speed (bottom) of forelimb movement.

\section{Figure 1-figure supplement 2. Histological verification of PT and IT neuronal labelling} a, Expression of fluorescently-labelled FLInChR in the deep layer 5 PT neurons of Sim1-cre mice. $\mathbf{b}$, Fluorescent labelling of the medullary pyramid in PT mice. c, Expression of FLInChR in the layer 5 IT neurons of TIx3-cre mice. $\mathbf{d}$, To compare the laminar distribution of PT and IT neurons in the motor cortex, the intensity of fluorescence was measured along a line oriented from the pial surface through M1 to the dorsal surface of STR. This distance was normalized to 1800 microns which is our estimate from the allen mouse brain atlas. The fluorescence intensity data were binned into 250 evenly spaced bins and averaged within each bin. The binned data were normalized to max intensity for each cell type.

\section{Figure 1-figure supplement 3. Histological and physiological estimation of the cortex border}

a, A sagittal (top) and coronal (bottom) view of a cleared mouse hemi brain imaged with light sheet microscopy. Green fluorescence indicates labeling of the deep layer 5 PT neurons and their projections to downstream areas such as striatum, superior colliculus and pons. Red fluorescence indicates probe tracks. Numbers in the top and bottom rows indicate medial-lateral and 
anterior-posterior coordinates relative to bregma, respectively. The length of the white scale bar = $1 \mathrm{~mm}$. b. Three dimensional rendering of probe tracks with the Allen Anatomical Template (AAT). Imaged 3D brain volumes were aligned to AAT, and each electrode on Neuropixels probe was assigned to a brain region using the probe geometry and Allen Reference Atlas (Methods). All cells recorded from electrodes located at the pial depth of $1.75 \mathrm{~mm}$ or upper (estimated by the manipulator) were assigned a motor cortical region. c, Estimated root mean square voltage (RMS) is plotted versus the pial depth. Note the trough indicating dearth of neural activity around the depth of $1.75 \mathrm{~mm}$, which is consistent with the histologically estimated cortical border. $\mathbf{d}$, Mean event rate is plotted versus the pial depth. An event is defined as voltage crossing (e.g. spikes) a threshold (80 $\mu V)$. Note the elevated event rates of the cortical depths. e, Threshold-crossing events are binned and counted based on the absolute raw amplitude for each pial depth. f, Mean event rates are plotted for each electrode site tiling the Neuropixel probe. Note the higher event rates within the cortical range as well as the dearth of events around the histologically estimated cortical border $(1.75 \mathrm{~mm})$. RMS and event rates were measured using codes written by Jennifer Colonell (https://github.com/jenniferColonell/Neuropixels_evaluation_tools).

\section{Figure 1-figure supplement 4. Summary of cortical and striatal neural population activity during task performance}

a, Mean z-score normalized activity aligned to reach threshold crossing and reward delivery (x axis) is plotted per inferred depth ( $y$ axis) relative to the pial surface for all individual recording sessions $(\mathrm{N}=10)$. $\mathbf{b}, \mathrm{MCtx}^{\mathrm{FL}}$ neural population activity of movement amplitude tertiles are projected onto the top three principal components. Neural trajectories indicate that at least partially separable populations of neurons are active during forelimb movements scaling with reach amplitude. Other populations appear to be active during reward collection.

\section{Figure 1-figure supplement 5. Projection of striatal neural population activity onto top three PCs}

Striatal neural population activity of movement amplitude tertiles are projected onto the top three principal components. Similar to the cortical data, neural trajectories indicate that at least partially separable populations of neurons are active during forelimb movements or reward collection.

\section{Figure 1-figure supplement 6 . Projection of $\mathrm{MCtx}^{\mathrm{FL}}$ population activity onto the cross-validated KN dimension}

Each panel represents MCtx ${ }^{\mathrm{FL}}$ data from each recording session. In each iteration, half of the trials were randomly selected and used to define the $\mathrm{KN}^{\mathrm{dim}}$, along which the variance of neural population activity was best explained by variance in forelimb movement amplitude. Data from the other half of the trials were projected to the $\mathrm{KN}^{\text {dim. }}$ (2-fold cross validation). Total 1000 iterations were run for data from each session, results of randomly selected 100 trials are plotted for simplicity.

Figure 2. Inhomogeneous laminar distribution of movement-timed activity in MCtx ${ }^{\mathrm{FL}}$ a, Top, Labelling of pons-projecting PT neurons (green) and the probe tract (red) with light sheet microscopy on a cleared hemibrain (see Figure 1 -figure supplement $2 \& 3$ for more coronal and sagittal images). Scale bar=1 $\mathrm{mm}$. Bottom, Probe tracks reconstructed in 3D volume were warped to Allen Anatomical Template (AAT), and each electrode site was annotated using Allen Reference Atlas (ARA). b, MCtx ${ }^{\mathrm{FL}}$ neural activity projected onto the top three PCs (Methods). PCs were classified as 'Move+', if the neural trajectory on each PC dimension (PC score) peaked before $+500 \mathrm{~ms}$ relative to the reach start. Other PCs that peaked afterwards with negative modulation during reach were classified as 'Move-'. c, Left, Weights of move+ PCs are plotted as a function of recording depth across all cortical neurons (solid circles). A dotted line indicates the histologically-verified cortical border (1.75 mm, see Methods and Figure 1-figure supplement 3). Right, Weights of move- PCs are plotted as a function of recording depth. $\mathbf{d}$, Weights of move+ and move- PCs significantly differ across cortical depths. e, Left, Performance of decoding illustrated on 20 repetitions (concatenated, 
randomized order) of joystick movements that yielded reward. Smoothed $\mathrm{x}$, y position trajectories ( $1 \mathrm{kHz}$ resolution; 300pt 3rd order Savitzky-Golay) are compared with prediction from a consensus linear decoder (see Methods) using 250 simultaneously recorded single units in MCtx ${ }^{\mathrm{FL}}$ and striatum. Center, Mean \pm SEM movement amplitude predicted by the decoder is plotted in blue. The orange trajectory represents the predicted amplitude from a decoder with unit-identity shuffling. Right, Boxplot of cross validation decoding performance (Pearson correlation between decoder prediction and observed trajectory) on test subsets for 50 training folds. f, Relative contribution of individual units can be informed by their weights comprising the decoder vector. The absolute valued weights were $z$-score normalized such that a greater value indicates a larger contribution in decoding. The weights are plotted versus the inferred recording depth to reveal the laminar inhomogeneity. Mean \pm 1 SD weights with 1000 laminar position shuffling are also plotted for comparison.

\section{Figure 3. Prevalence of motor command-like activity in IT neurons}

a, Normalized mean \pm SEM neural activity before and during optical silencing (tagging) of pons-projecting $\mathrm{PT}^{+}$neurons. $\mathbf{b}$, same as $\mathbf{a}$ but of striatum-projecting $\mathrm{IT}^{+}$neurons. $\mathbf{c}$, Change of the mean firing rate of the individual neurons during optical tagging is plotted as a function of the inferred recording depth ( $x$ axis). Units with a significant change are plotted with filled circles with the latency of half-maximal firing rate change color-coded. Note that the tagged $\mathrm{PT}^{+}$and $\mathrm{IT}^{+}$neurons are located in the estimated depths of layer 5 as expected. d-e, Raw voltage traces showing spike activity of example $\mathrm{PT}^{+}(\mathrm{d})$ and $\mathrm{IT}^{+}$(e) units with the amplitude of joystick movement superimposed at the top. f, Left, Trial by trial activity of an example $\mathrm{PT}^{+}$neuron to laser (60 trials, $594 \mathrm{~nm}$ ) during optotagging after completion of task performance. More examples are shown in Figure 3-figure supplement 1. Right, Activity of the same $\mathrm{PT}^{+}$neuron aligned to the reach start during task performance. $\mathbf{g}$, Z-score normalized activity of all individual $\mathrm{PT}^{+}$neurons aligned to the reach start during task performance. $\mathbf{h}$, Left, Trial by trial activity of an example $\mathrm{IT}^{+}$neuron to laser during optotagging. Right, Activity of the same $\mathrm{IT}^{+}$neuron aligned to the reach start. i, Z-score normalized activity of all individual $\mathrm{IT}^{+}$neurons aligned to the reach start. $\mathbf{j}$, Normalized mean $\pm \mathrm{SEM}$ activity of $\mathrm{PT}^{+}, \mathrm{IT}^{+}$neural populations aligned to reach threshold crossing (ReachT) and reward delivery. The mean activity of the rest (untagged) of $\mathrm{MCtx}{ }^{\mathrm{FL}}$ is plotted in dotted curves for comparison. $\mathbf{k}$, The cumulative distribution of the timing for peak activity is plotted for $\mathrm{PT}^{+}$and $\mathrm{IT}^{+}$neural populations. Distribution of the rest (untagged) of MCtx ${ }^{\mathrm{FL}}$ is plotted in dotted curves for comparison. I, The cumulative distribution of the reward to reach activity ratio is plotted for $\mathrm{PT}^{+}$and $\mathrm{IT}^{+}$neural populations. The ratio greater than 1 means that the corresponding unit displayed a greater response during the reward epoch than the movement epoch of same lengths.

\section{Figure 3-figure supplement 1. $\mathrm{PT}^{+}$and $\mathrm{IT}^{+}$neuronal activity during task performance and optotagging}

Blue-colored rasters in the left column illustrate trial by trial individual neuronal responses during task performance (left panel of each pair, aligned to reach start) with significant inhibitory responses during optotagging (right panel of each pair, aligned to laser onset) in Sim1-Cre (KJ18Gsat) mice injected with rAAV2-retro-CAG-Flex-FLInChR-mVenus to the pons. Each row represents each trial. The mean \pm SEM spike rate $(\mathrm{Hz})$ is superimposed. Numbers on the left and right ordinates of each plot indicate the number of trial and firing rate in $\mathrm{Hz}$, respectively. Green-colored rasters in the right column illustrate trial by trial $\mathrm{IT}^{+}$individual neuronal responses during task performance (left panels) and optotagging (right panels) in Tlx3-Cre (PL56Gsat) mice.

\section{Figure 4. Cell-type specific imaging shows prominent movement-timed activity in IT neurons of superficial layer 5 MCtx ${ }^{\mathrm{FL}}$}

a, Two-photon calcium imaging was performed from left MCtx ${ }^{\mathrm{FL}}$, targeting either layer 5b PT or layer 5 a IT neurons (separate experiments). Schematic shows the different brain-wide projection targets of the two cell types. b, Top left: Histology from 2 imaged mice, one from each of the two mouse lines. Scale bar 100 microns, images are matched for scale. Top right: example field of view. Bottom 
rows: Green traces are inferred spike rates of randomly selected IT neurons aligned to behavioral variables below. c, Mean normalized activity traces aligned to reach threshold crossing and reward delivery for every unit in the dataset, grouped by projection neuron type. Units are ranked by time of peak activity determined using the unplotted half of trials. Each row normalized to its peak activation. d, Top row shows the average normalized joystick speed and lick rate. Bottom row shows mean PT and IT activity. All are aligned to reward delivery. IT neurons show prominent peri-movement activation, whilst PT peak activity occurs later. Units were mean averaged for each projection target, then resulting average was normalized to range 0-1. e, Normalized inferred spike rate for individual units with positive or negative PC1 loadings are plotted. Colored dots on the left reflect the cell type. For PCA, PT units were randomly subsampled to match the size of the IT population. Individual principal components, and additional example units, are provided in Figure 4-figure supplement 1. f, Unit weights on the first and second principal components. g, Histogram of unit weights on principal component 1 for IT and PT neurons.

\section{Figure 4-figure supplement 1. Further information about spike deconvolution from calcium imaging data and PCA with the inferred spike rate data.}

a, Illustration of spike deconvolution. Panel shows 5 example regions of interest, each of two rows. Top row for each unit (blue) shows the dF/F trace, with the row beneath (red) showing the inferred spike activity metric. $\mathbf{b}$, a zoomed-in portion for three units from a. c, Structure of first four principal components of neural activity across all units in the dataset, aligned to reward. $\mathbf{d}$, The fraction of explained variance for the top 10 principal components in the dataset. e, left, The normalized inferred spike rates of representative units with most positive (top 100 rows) and negative (bottom 100 rows) weights for PC1 are plotted. Format same as Figure 3e. right, The normalized inferred spike rates of representative units with positive (top 100 rows) and negative (bottom 100 rows) weights for PC2 are plotted.

\section{Figure 5. Cell-type specific individual neuronal correlation with- and neural population decoding of movement kinematics}

a, Individual $\mathrm{PT}^{+}$units are plotted based on their normalized movement-timed activity along $\mathrm{X}$ axis and their activity modulation as a function of movement amplitude along $Y$ axis (regression coefficients, $\beta$ ). For instance, a unit in the first quadrant is the one that increased its firing rate during movement with a positive correlation with the movement amplitude. Blue-filled circles represent $\mathrm{PT}^{+}$units with a significant regression coefficient ( $t$ test, $\mathrm{a}=0.05$ ). Gray circles represent the rest of $\mathrm{MCtx}{ }^{\mathrm{FL}}$ units that were not tagged. Fisher's exact test against a uniform distribution of $\mathrm{PT}^{+}$ units across quadrants, $\mathrm{p}=0.84)$. $\mathbf{b}$, The vast majority of the individual $\mathrm{IT}^{+}$units located in the first quadrant (Fisher's exact test, $\mathrm{p}=0.0056$ ). Green-filled circles represent $\mathrm{IT}^{+}$units with a significant regression coefficient. Gray circles represent the rest of $\mathrm{MCtx} \mathrm{FL}^{\mathrm{L}}$ units that were not tagged. $\mathbf{c}$, Squared Pearson correlation between normalized firing rate and reach amplitude are plotted for individual $\mathrm{PT}^{+}$and $\mathrm{IT}^{+}$units color-coded by their mean movement-timed activity. $\mathbf{d}$, To gauge how informative the $\mathrm{PT}^{+}$neuronal population activity was of the movement kinematics relative to other subpopulations, contributions to decoder performance of the separate neural populations either identified by optotagging $\left(\mathrm{PT}^{+}\right)$or inferred from anatomical position (see Methods) are plotted. e, Naive Bayes classifiers were trained with cross validation to predict movement amplitude tertile of a given unlabeled trial using all units or separate populations of units either identified by optotagging $\left(\mathrm{PT}^{+}, \mathrm{IT}^{+}\right)$or inferred from anatomical position.

\section{Figure 6. $\mathrm{MCtx}^{\mathrm{FL}}$ IT neurons are necessary for control of forelimb movement kinematics}

a, Schematic of closed-loop inactivation paradigm used in the variable amplitude joystick task. b, Left, Mean \pm SEM reach amplitude of unperturbed (green) and IT inactivation (orange) trials. Right, Mean reach amplitude of unperturbed and IT inactivation trials broken out for individual mice. c, Left, Mean \pm SEM reach speed of unperturbed (green) and IT inactivation (orange) trials. Right, Mean 
reach speed of unperturbed and IT inactivation trials. $\mathbf{d}$, Left, Mean \pm SEM reach amplitude of unperturbed (blue) and PT inactivation (orange) trials. Right, Mean reach amplitude of unperturbed and PT inactivation trials broken out for individual mice. e, Left, Mean $\pm \mathrm{SEM}$ reach speed of unperturbed (blue) and PT inactivation (orange) trials. Right, Mean reach speed of unperturbed and PT inactivation trials. $\mathbf{f}$, Left, The mean 2D joystick trajectory of PT inactivation versus control trials from an example session, illustrating the lateral deviation ( $X$ axis) due to PT inactivation. Center, The mean \pm SEM joystick $X$ trajectory is plotted for all PT inactivation sessions. Right, The mean \pm SEM joystick X trajectory is plotted for all IT inactivation sessions. *** $p<0.001, * * p<0.01, * p<0.05$.

\section{Figure 7. Inactivation of PT and IT neurons oppositely affect striatal activity}

a, 3D visualization of complete single neuron reconstructions (Winnubst et al., 2019) from the PT (top) and IT (bottom) anatomical classes, illustrating integration of PT and IT neuronal projections in striatum. $\mathbf{b}$, Change in the $\mathrm{PT}^{+}$neuronal activity due to the movement-triggered inactivation during task performance. $\mathbf{c}$, Change in the $\mathrm{IT}^{+}$neuronal activity due to the movement-triggered inactivation during task performance. $\mathbf{d}$, Change in the downstream striatal activity during PT or IT neuronal inactivation illustrates opposite effects. $\mathbf{e}$, The effect of PT inactivation on the firing rate of putative medium spiny neurons (left) and putative interneurons (right). f, Left, g, Left, dSTR neural population activities of all sessions are projected to the $\mathrm{KN}$ dimension and plotted separately for movement amplitude tertiles. Center, PT inactivation did not lead to a significant change in the KN ${ }^{\text {dim. }}$. Right, IT inactivation led to a significant decrease in the $\mathrm{KN}^{\text {dim. }}$ projection score.

\section{Figure 7-figure supplement 1. Robust $\mathrm{PT}^{+}$and $\mathrm{IT}^{+}$neuron inactivation during task performance}

a, An example $\mathrm{PT}^{+}$neuron displays a robust inactivation by the laser triggered at the earliest detection of reach in randomly selected trials (top raster rows; bottom raster rows represent control trials). The mean \pm SEM spike density $(\mathrm{Hz})$ functions are superimposed for laser and control trials. $\mathbf{b}$, Change of all individual $\mathrm{PT}^{+}$neuronal activity by opto-silencing aligned to the movement onset. $\mathbf{c}, \mathrm{An}$ example $\mathrm{IT}^{+}$neuron displays a robust inactivation by the laser. $\mathbf{d}$, Change of all individual $\mathrm{IT}^{+}$ neuronal activity by opto-silencing. 
bioRxiv preprint doi: https://doi.org/10.1101/772517; this version posted February 22, 2021. The copyright holder for this preprint (which was not certified by peer review) is the author/funder, who has granted bioRxiv a license to display the preprint in perpetuity. It is made available under aCC-BY-NC-ND 4.0 International license.
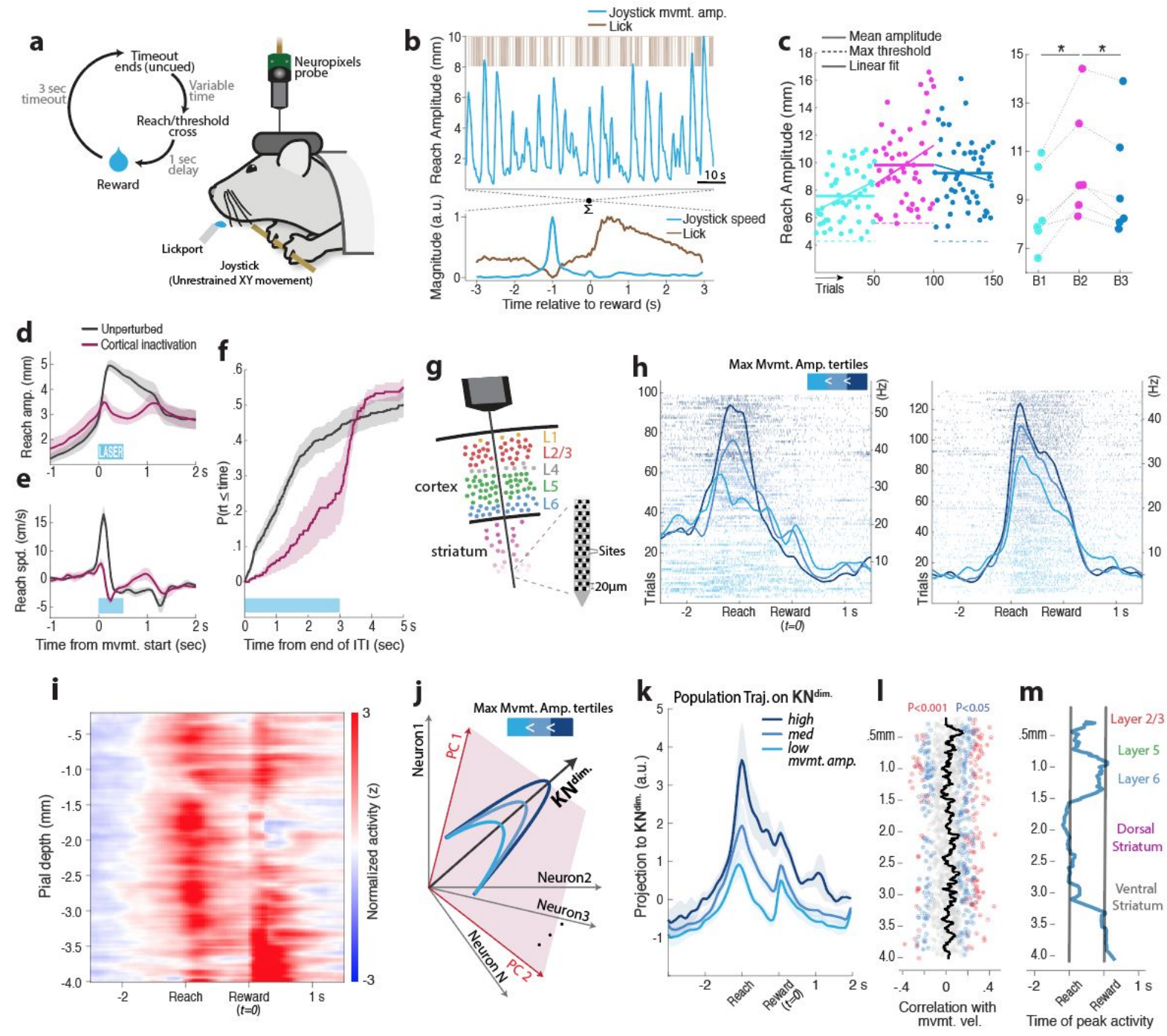

Figure 1 
a

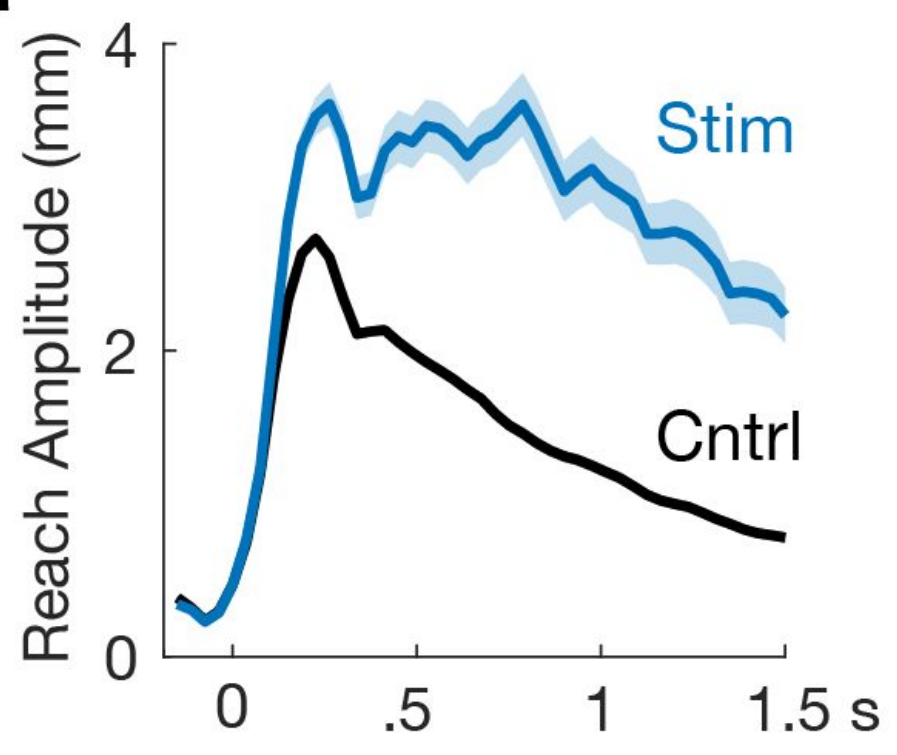

b

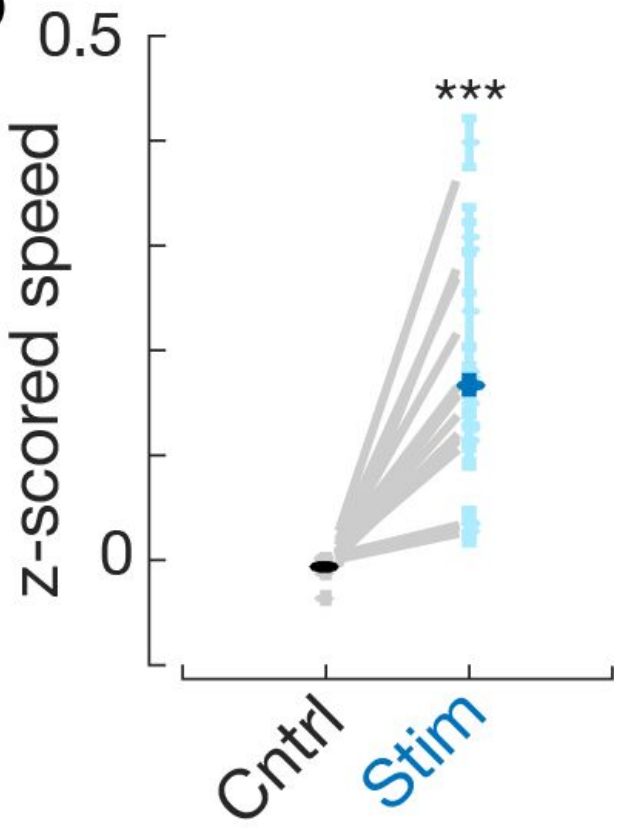

Figure 1-figure supplement 1 
bioRxiv preprint doi: https://doi.org/10.1101/772517; this version posted February 22, 2021. The copyright holder for this preprint (which was not certified by peer review) is the author/funder, who has granted bioRxiv a license to display the preprint in perpetuity. It is made available under aCC-BY-NC-ND 4.0 International license.

a

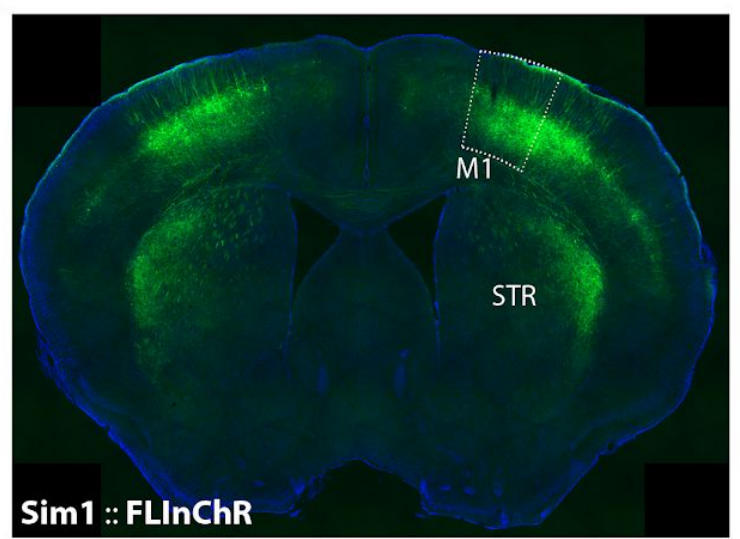

b

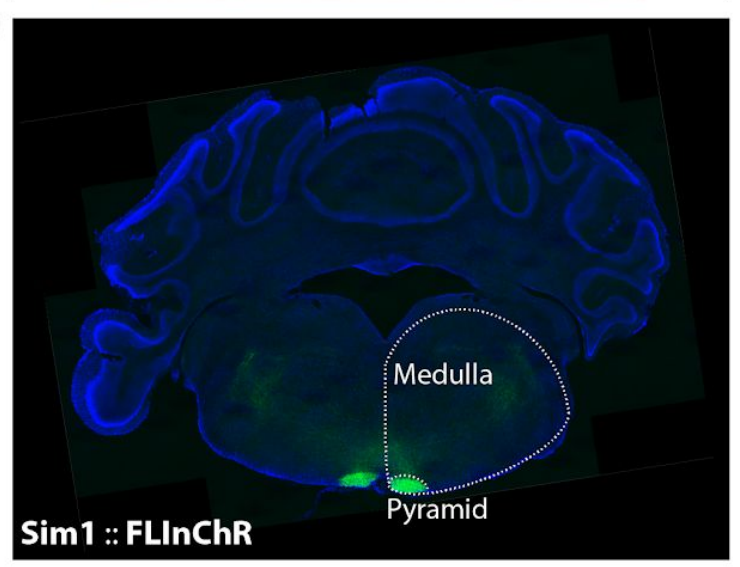

C
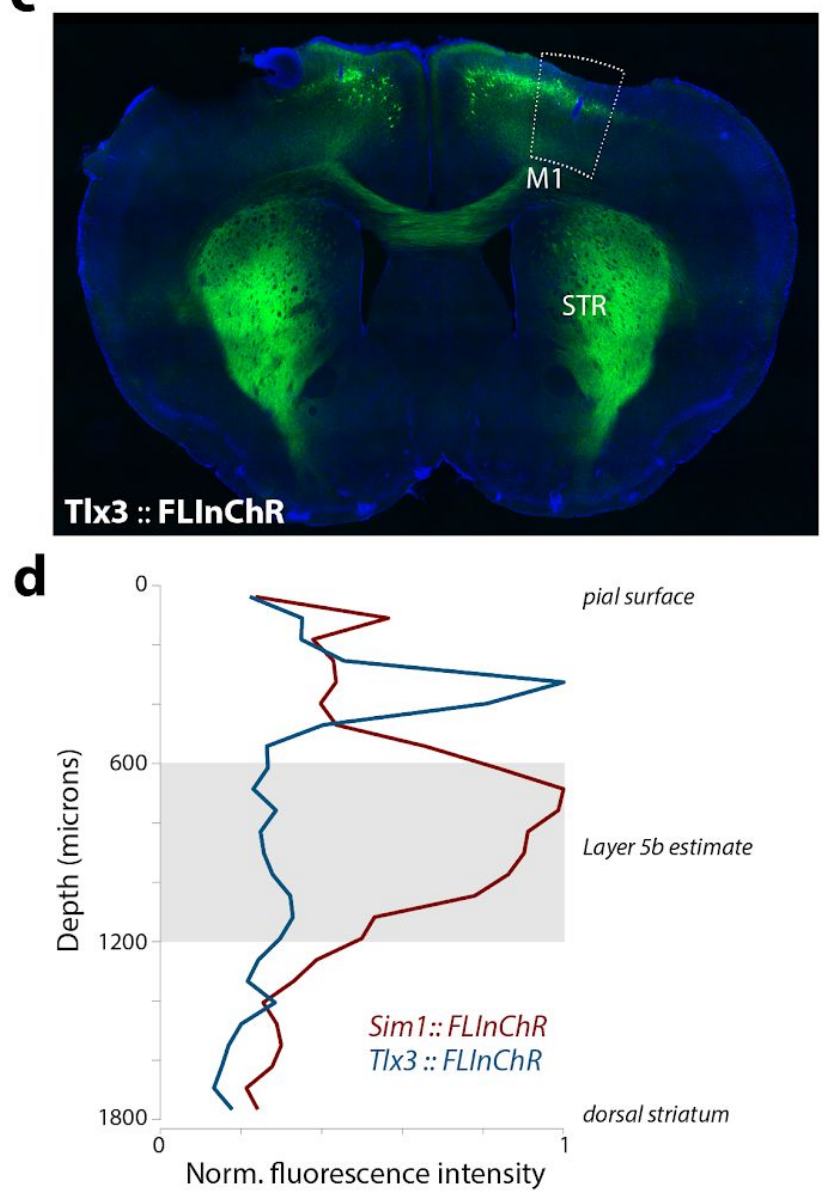

Figure 1-figure supplement 2 
bioRxiv preprint doi: https://doi.org/10.1101/772517; this version posted February 22, 2021. The copyright holder for this preprint (which was not certified by peer review) is the author/funder, who has granted bioRxiv a license to display the preprint in perpetuity. It is made available under aCC-BY-NC-ND 4.0 International license.
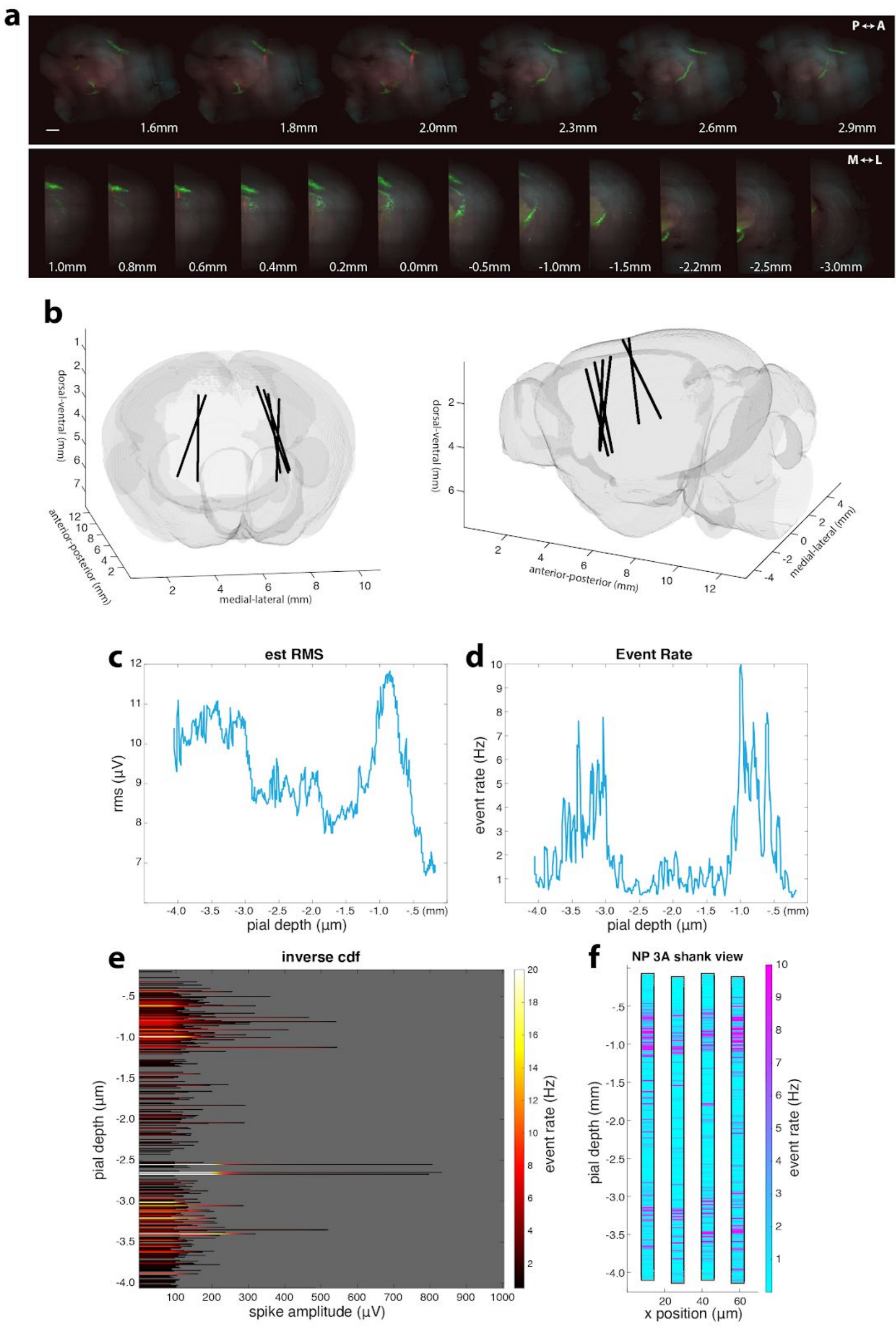
bioRxiv preprint doi: https://doi.org/10.1101/772517; this version posted February 22, 2021. The copyright holder for this preprint (which was not certified by peer review) is the author/funder, who has granted bioRxiv a license to display the preprint in perpetuity. It is made available under aCC-BY-NC-ND 4.0 International license.
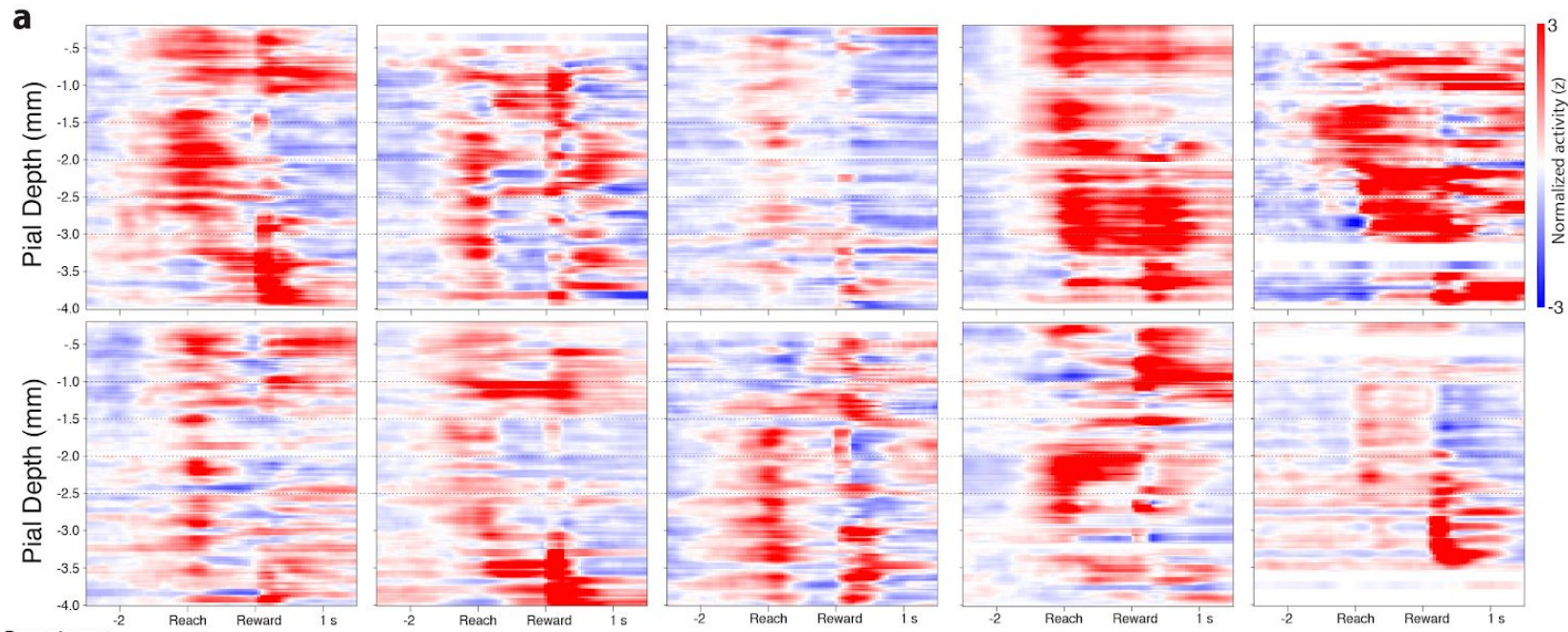

b
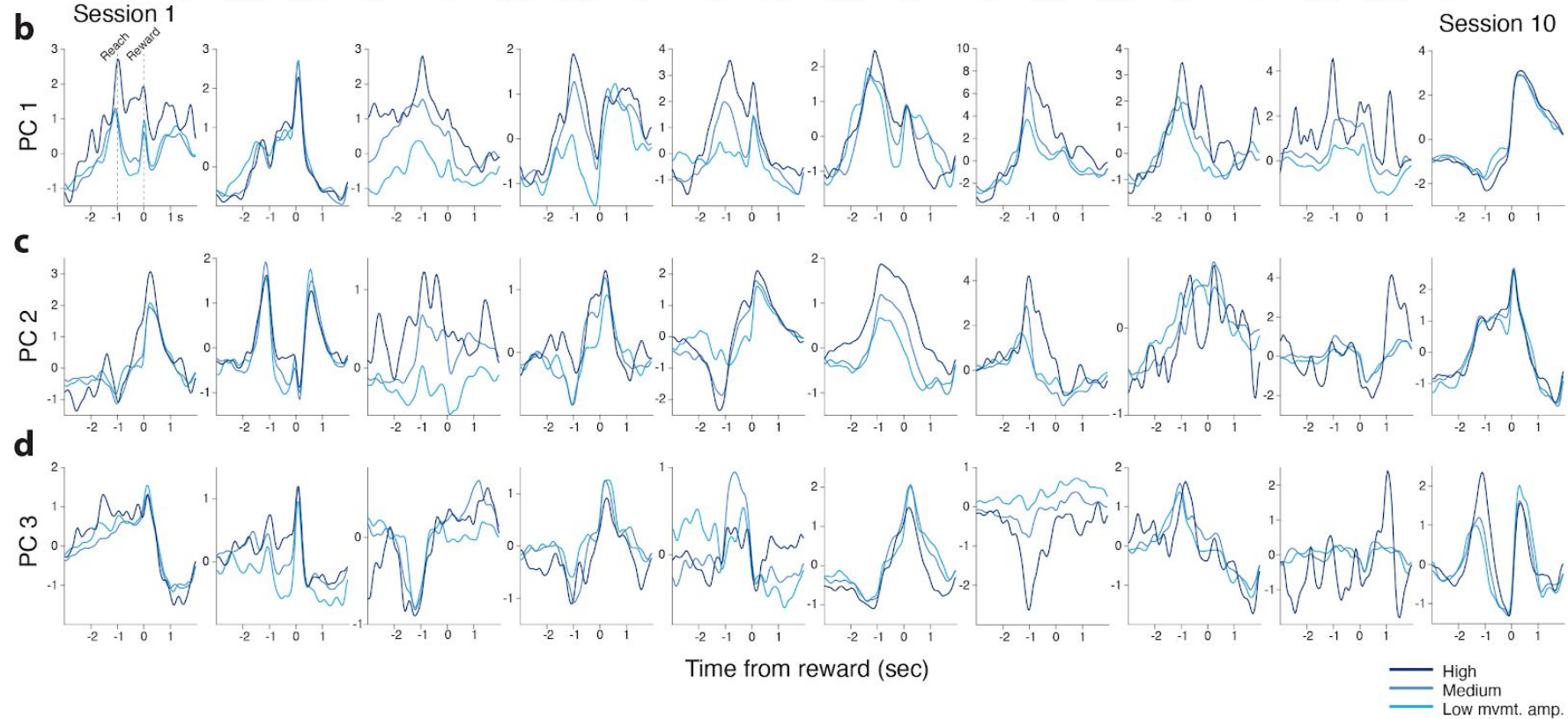

Figure 1-figure supplement 4 
bioRxiv preprint doi: https://doi.org/10.1101/772517; this version posted February 22, 2021. The copyright holder for this preprint (which was not certified by peer review) is the author/funder, who has granted bioRxiv a license to display the preprint in perpetuity. It is made available under aCC-BY-NC-ND 4.0 International license.

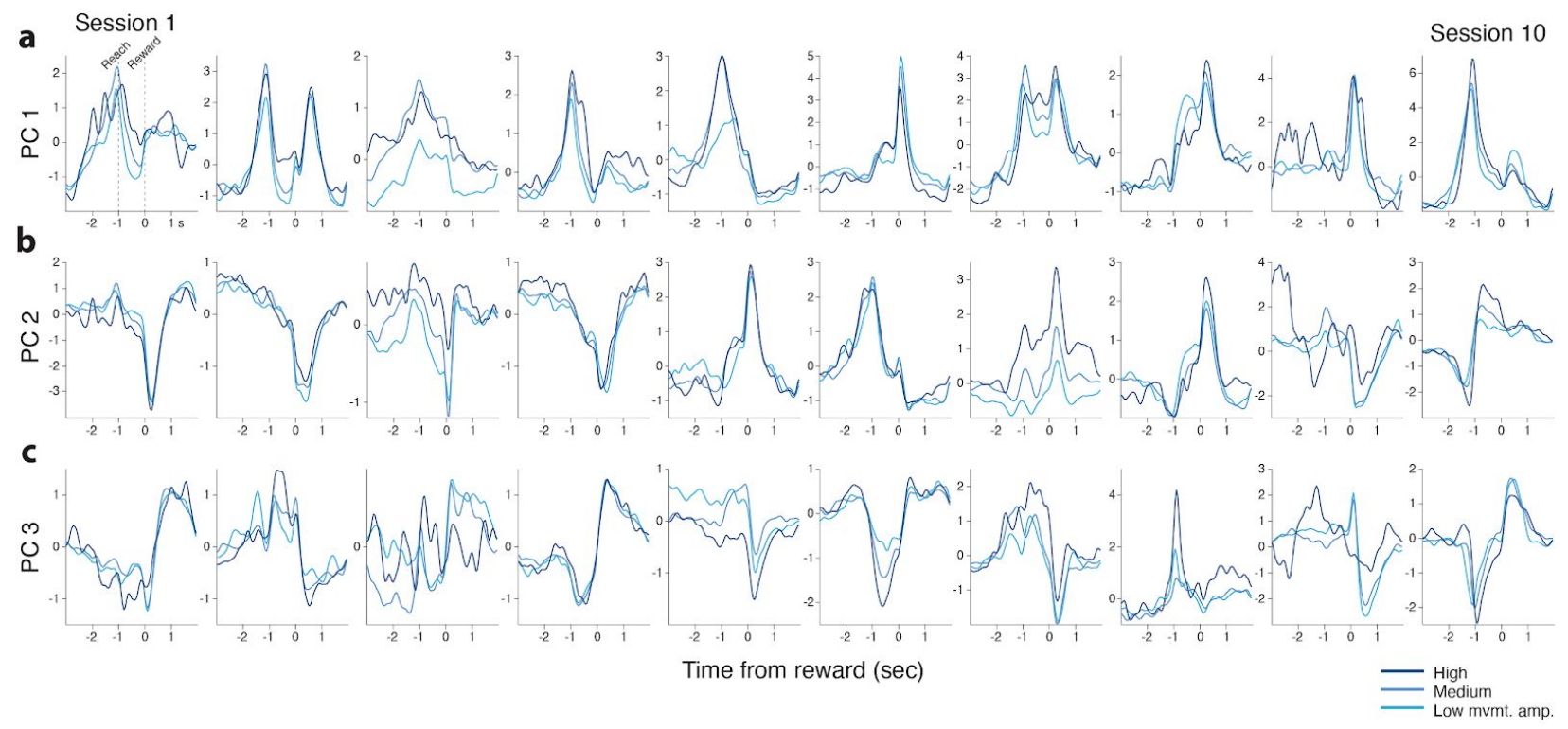

\section{Figure 1-figure supplement 5}
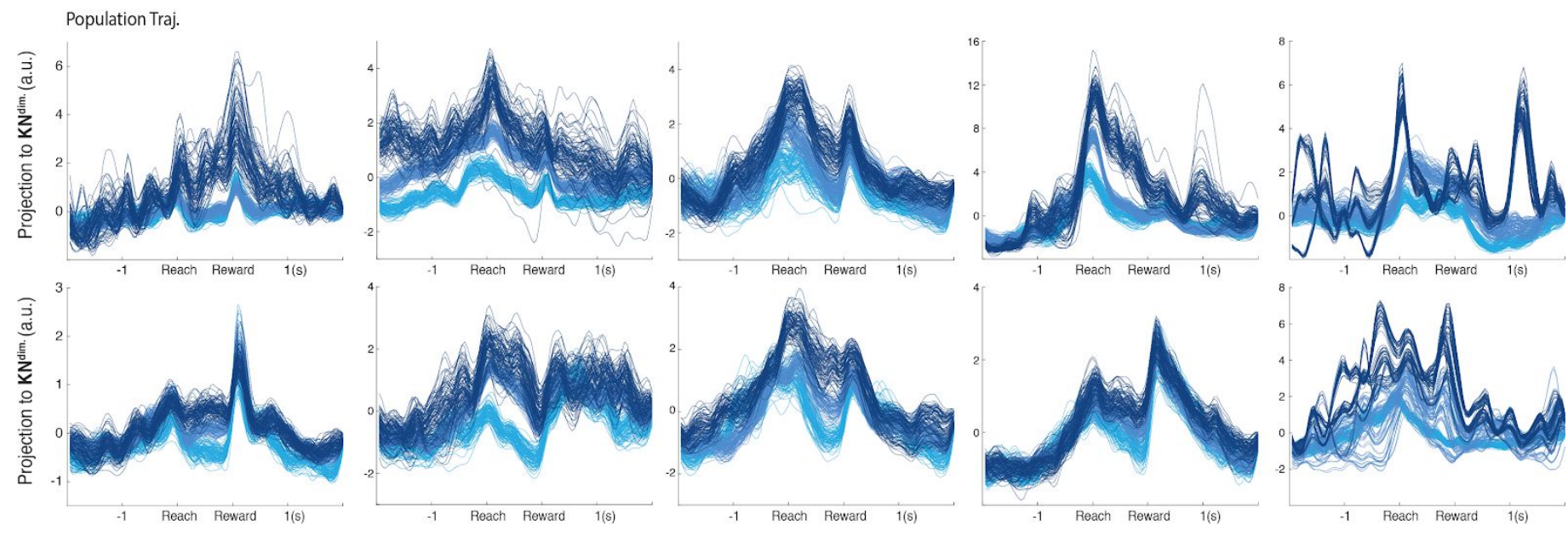

Figure 1-figure supplement 6 
bioRxiv preprint doi: https://doi.org/10.1101/772517; this version posted February 22, 2021. The copyright holder for this preprint (which was not certified by peer review) is the author/funder, who has granted bioRxiv a license to display the preprint in perpetuity. It is made available under aCC-BY-NC-ND 4.0 International license.

a
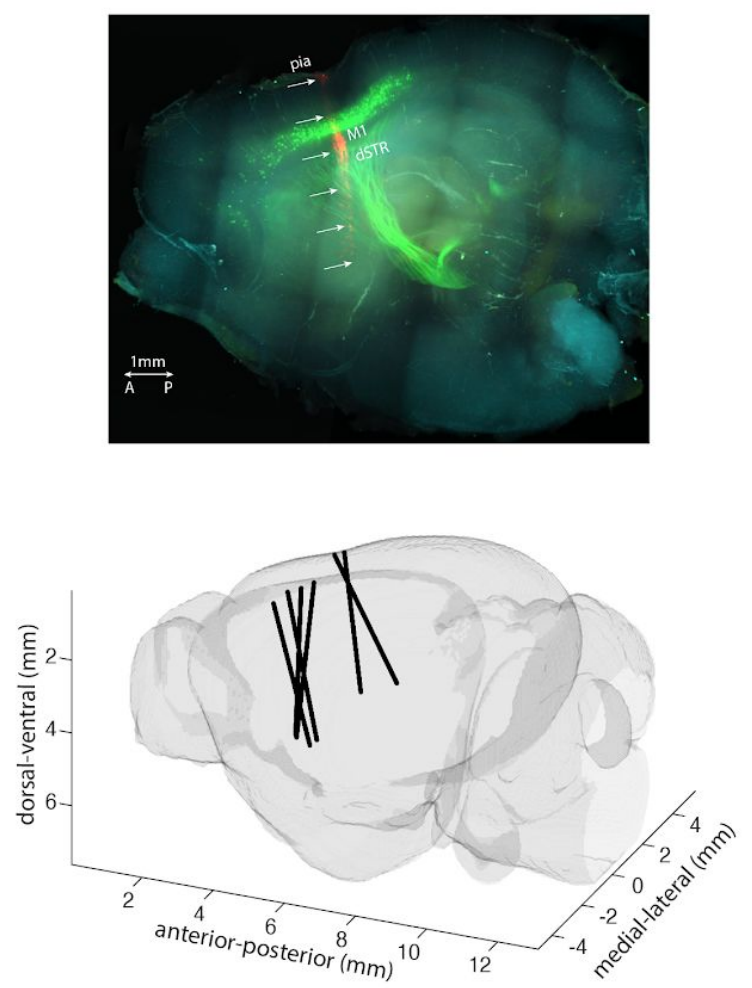

e

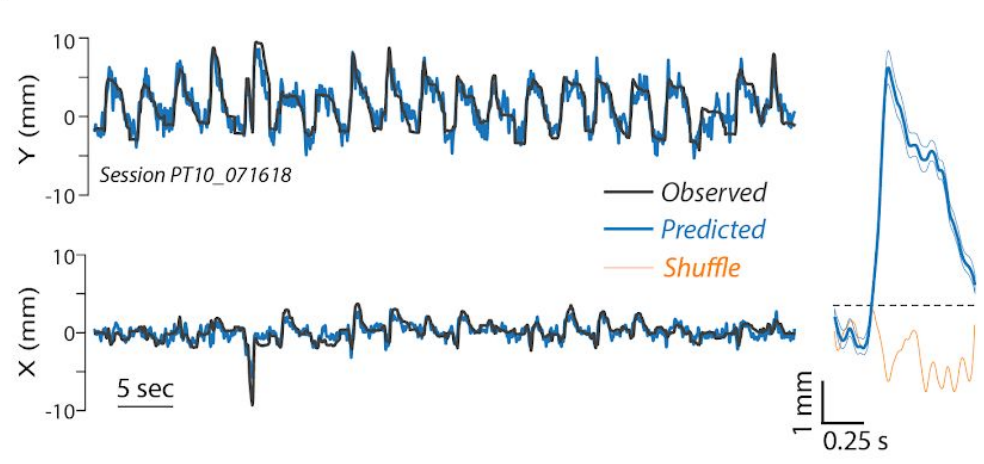

Figure 2 b
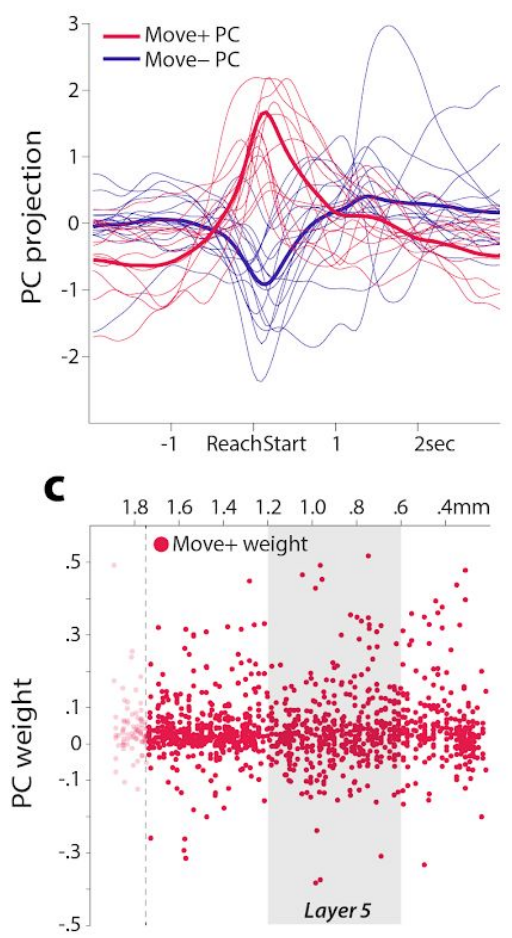

d
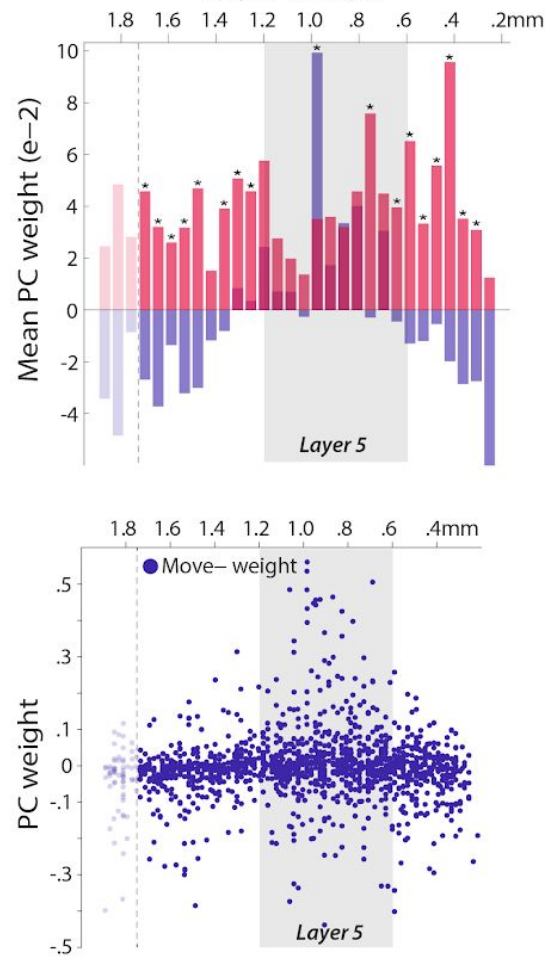

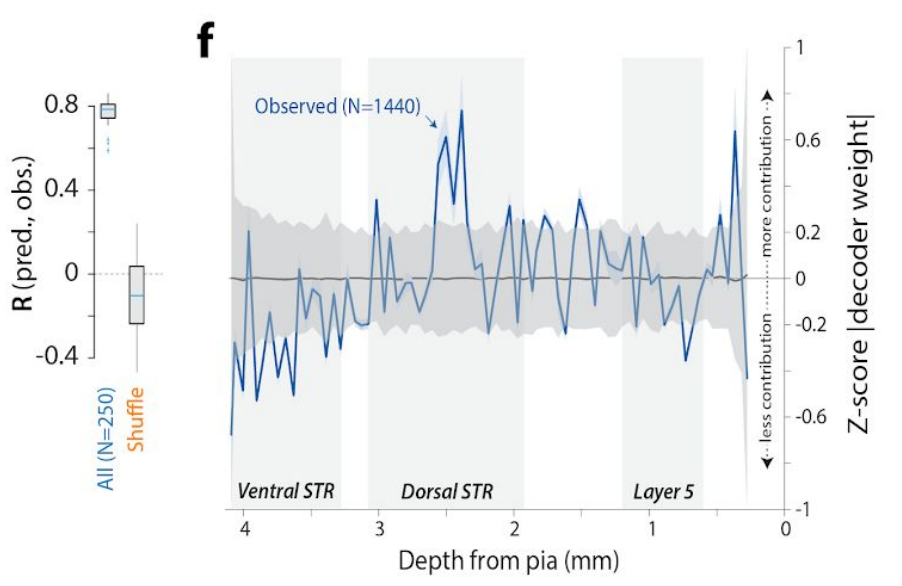


bioRxiv preprint doi: https://doi.org/10.1101/772517; this version posted February 22, 2021. The copyright holder for this preprint (which was not certified by peer review) is the author/funder, who has granted bioRxiv a license to display the preprint in perpetuity. It is made available under aCC-BY-NC-ND 4.0 International license.
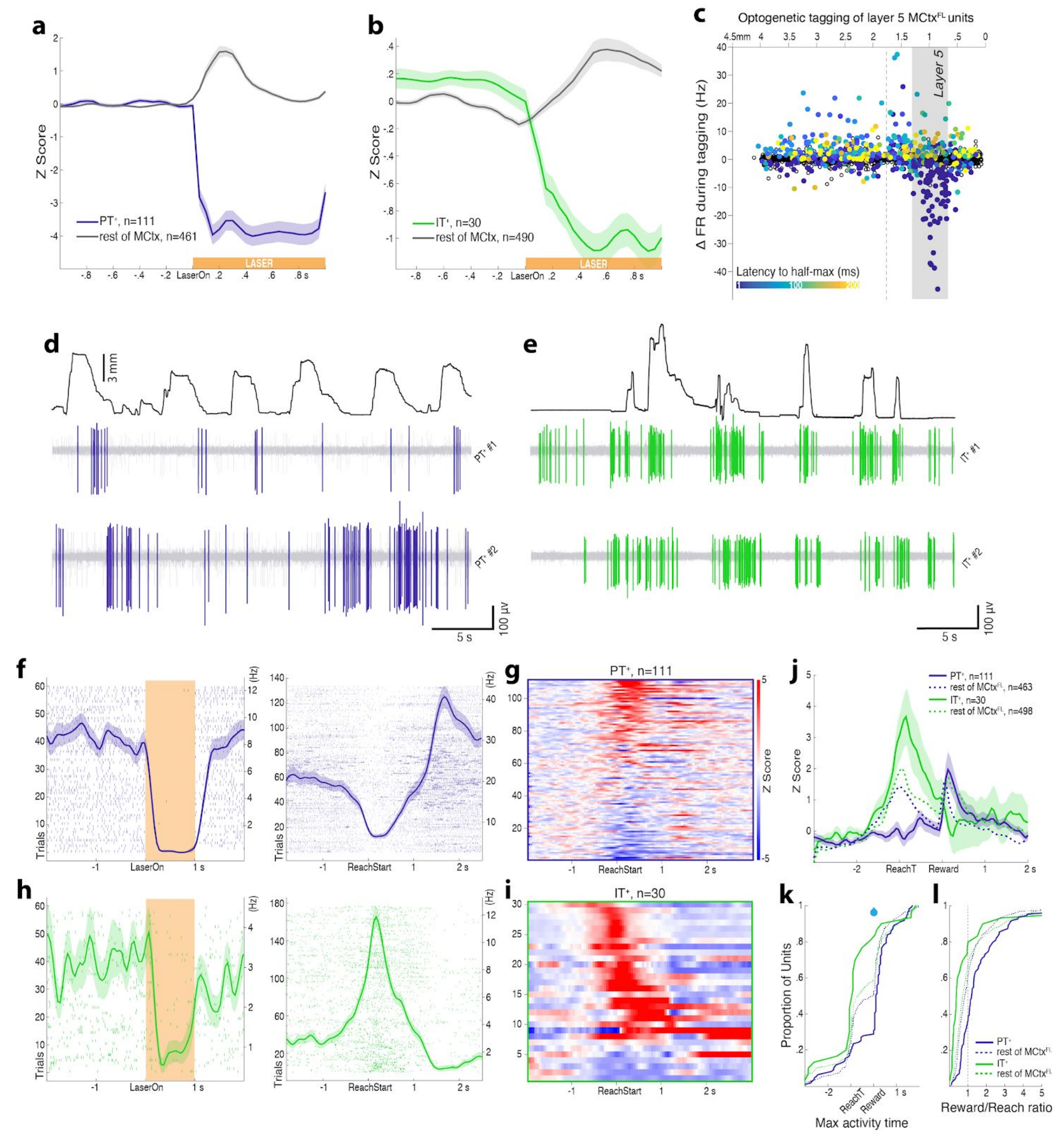

Figure 3 
bioRxiv preprint doi: https://doi.org/10.1101/772517; this version posted February 22, 2021. The copyright holder for this preprint (which was not certified by peer review) is the author/funder, who has granted bioRxiv a license to display the preprint in perpetuity. It is made available under aCC-BY-NC-ND 4.0 International license.
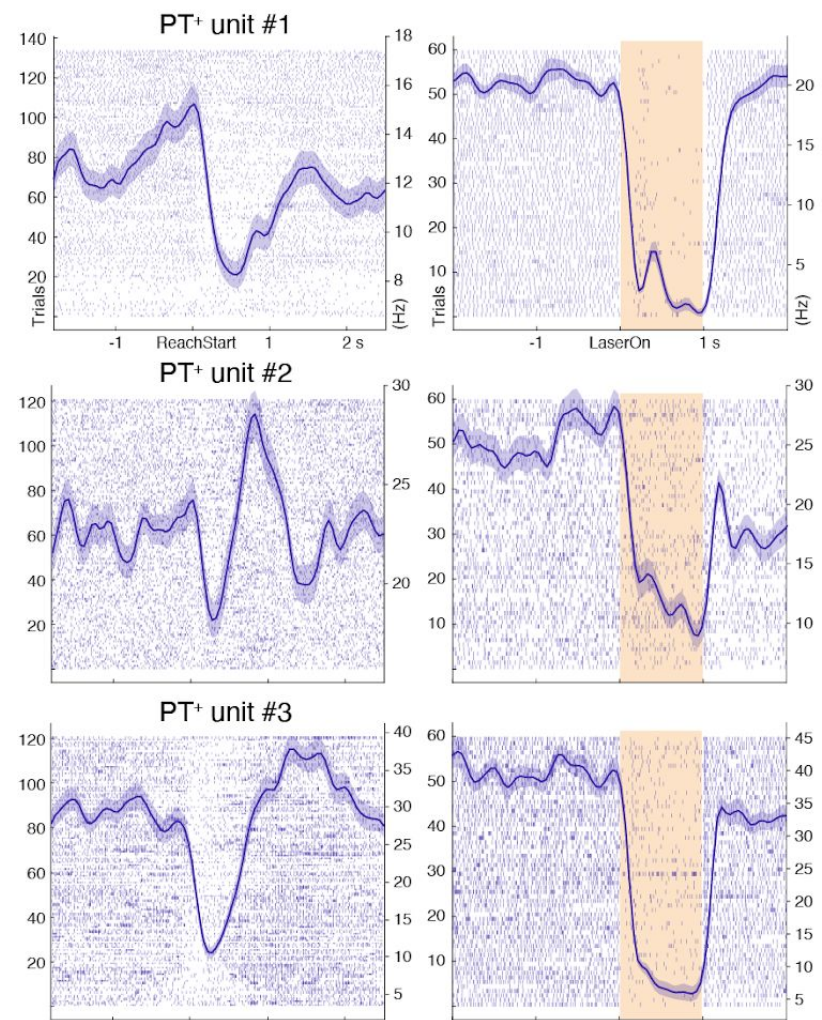

$\mathrm{PT}^{+}$unit \#4
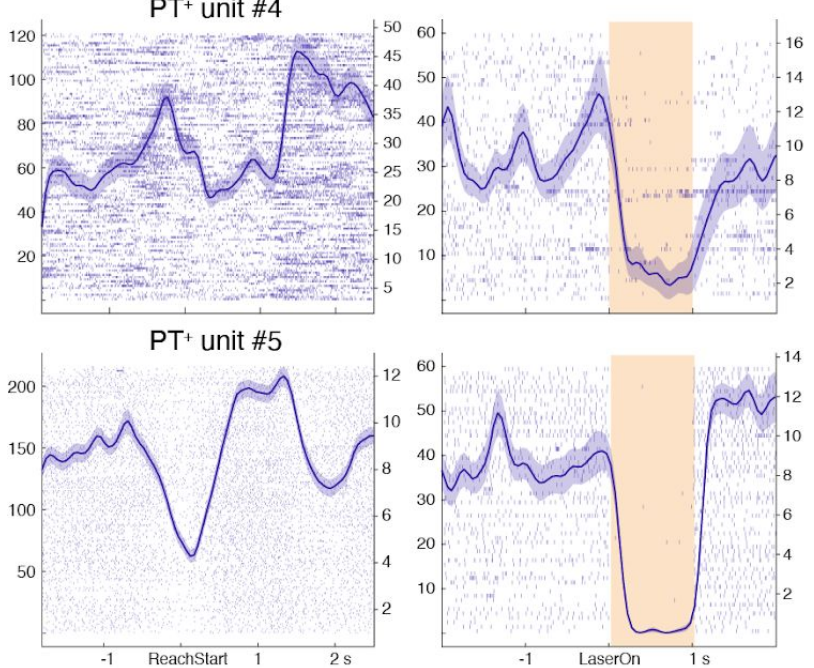
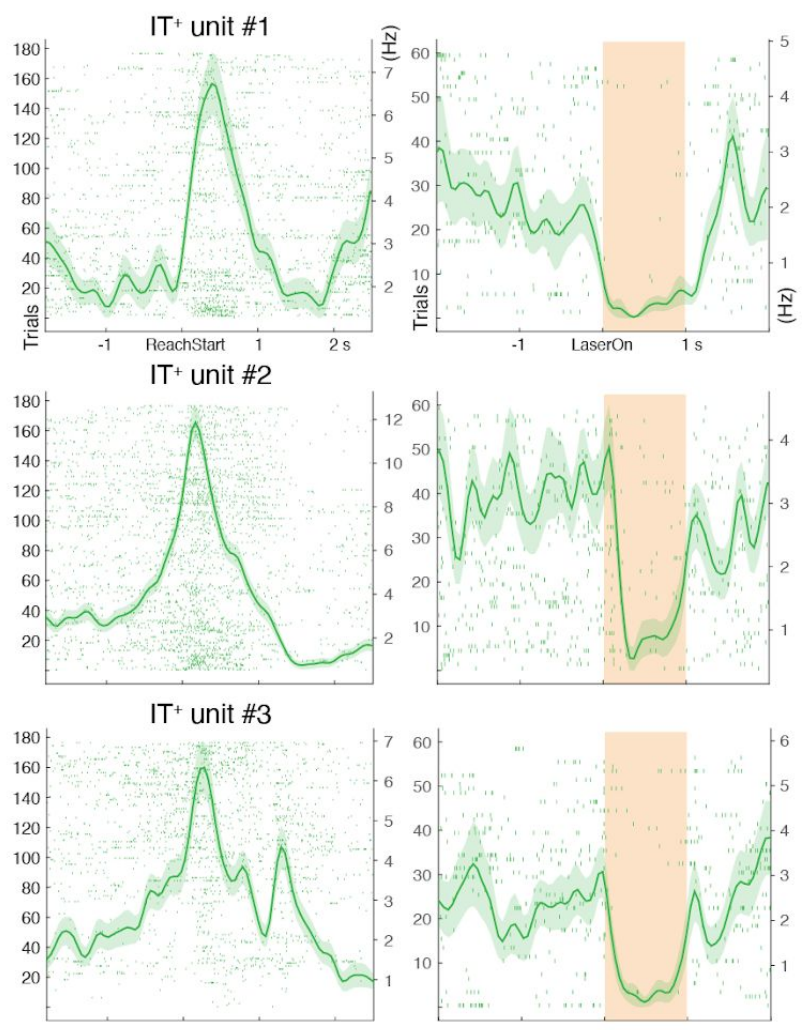

$\mathrm{IT}^{+}$unit \#4
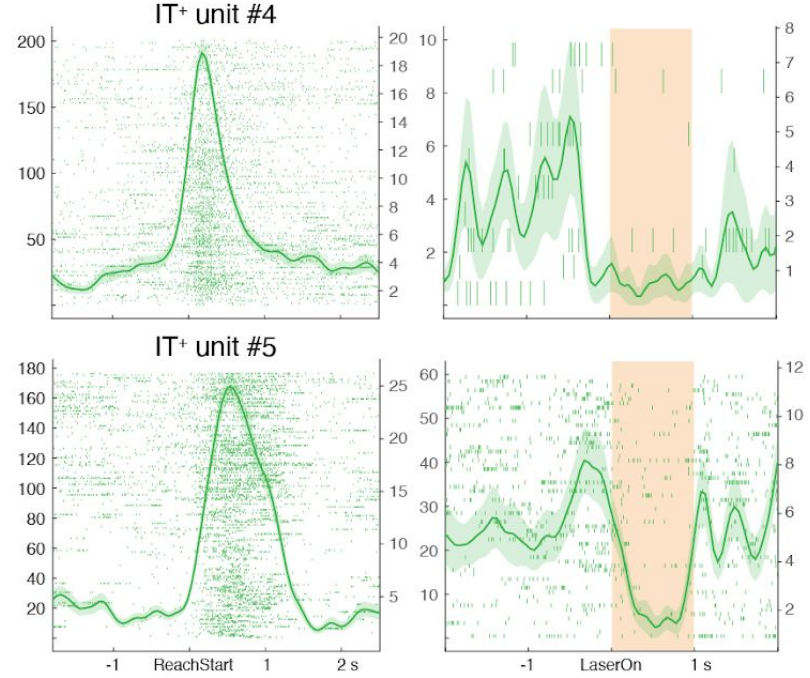

\section{Figure 3-figure supplement 1}


bioRxiv preprint doi: https://doi.org/10.1101/772517; this version posted February 22, 2021. The copyright holder for this preprint (which was not certified by peer review) is the author/funder, who has granted bioRxiv a license to display the preprint in perpetuity. It is made available under aCC-BY-NC-ND 4.0 International license.

a

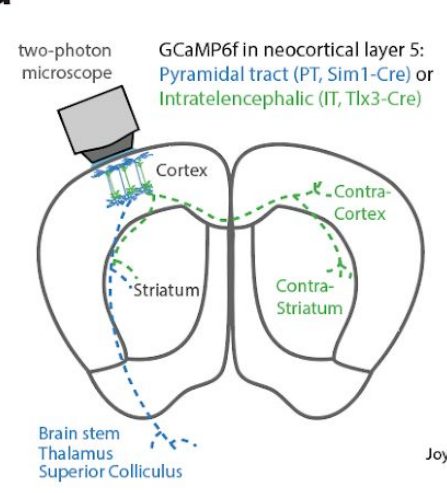

b

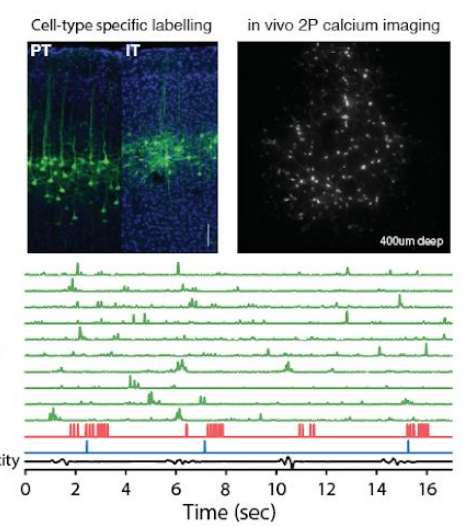

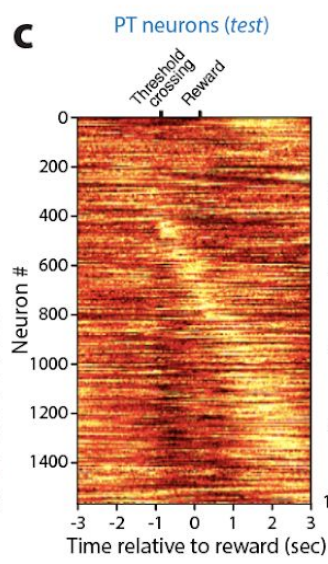

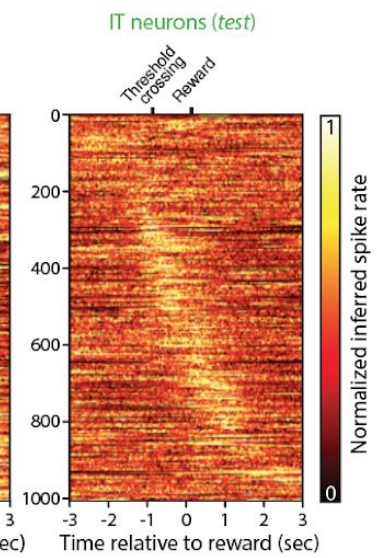

$\mathbf{g}$

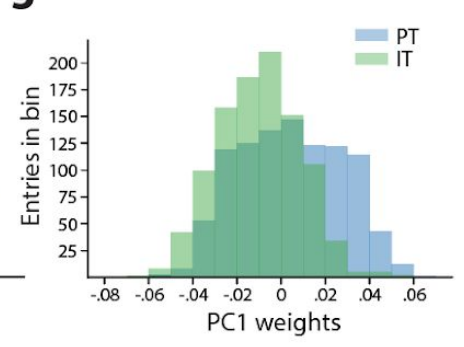

Figure 4 
bioRxiv preprint doi: https://doi.org/10.1101/772517; this version posted February 22, 2021. The copyright holder for this preprint (which was not certified by peer review) is the author/funder, who has granted bioRxiv a license to display the preprint in perpetuity. It is made available under aCC-BY-NC-ND 4.0 International license.
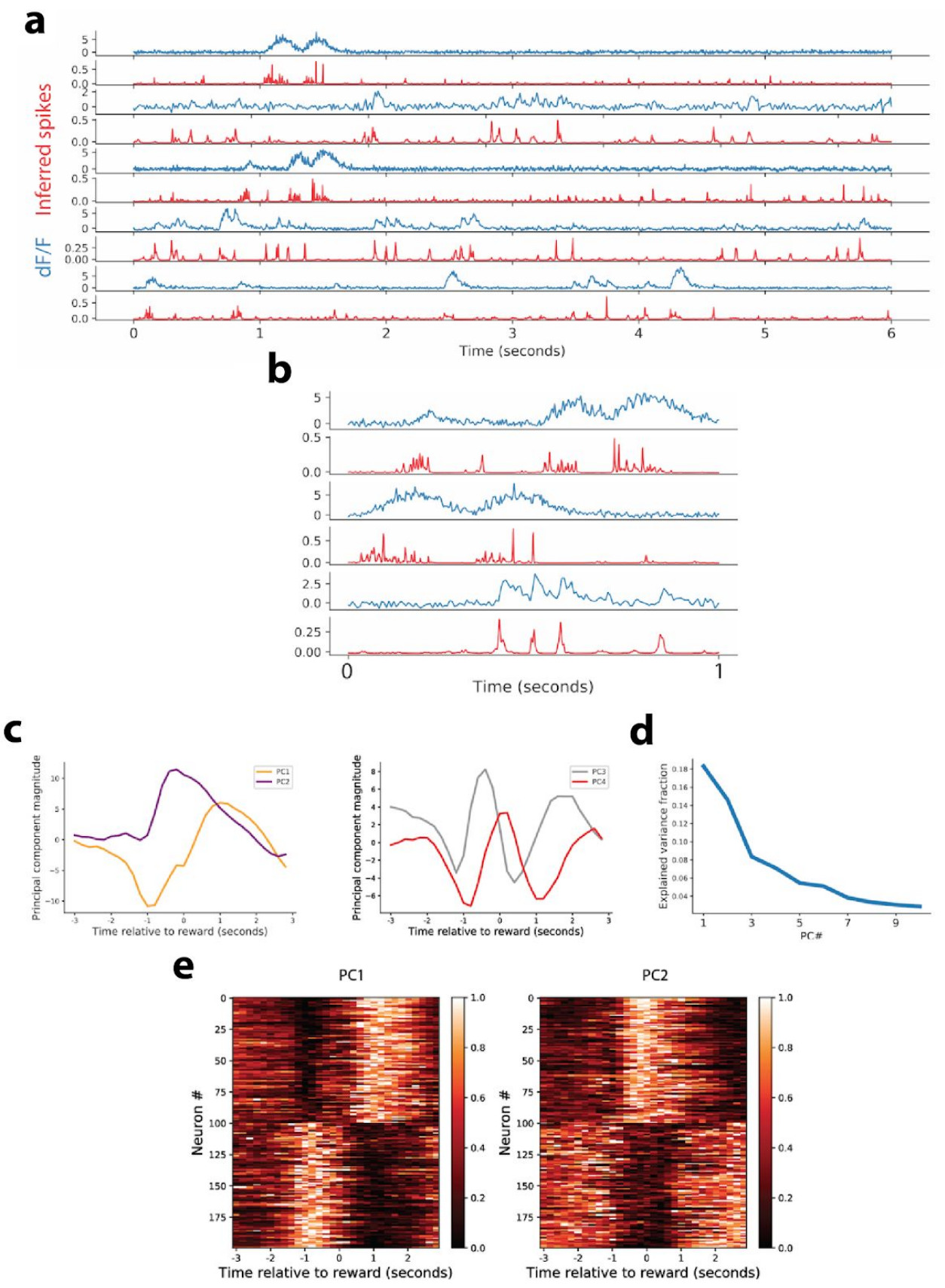

Figure 4-figure supplement 1 


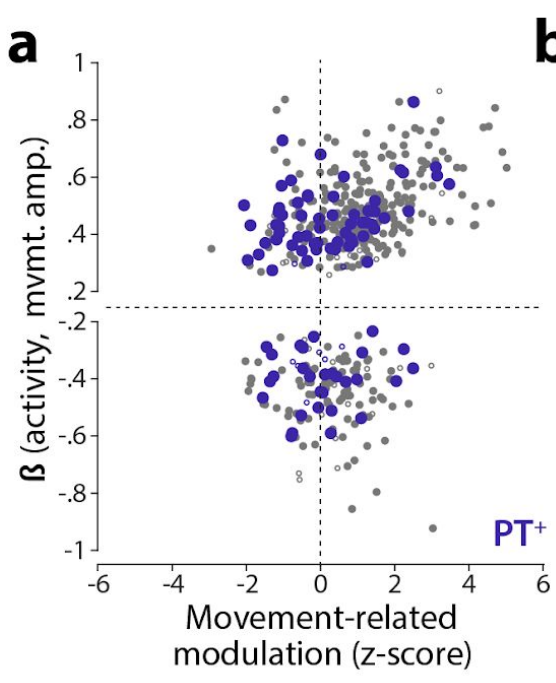

d

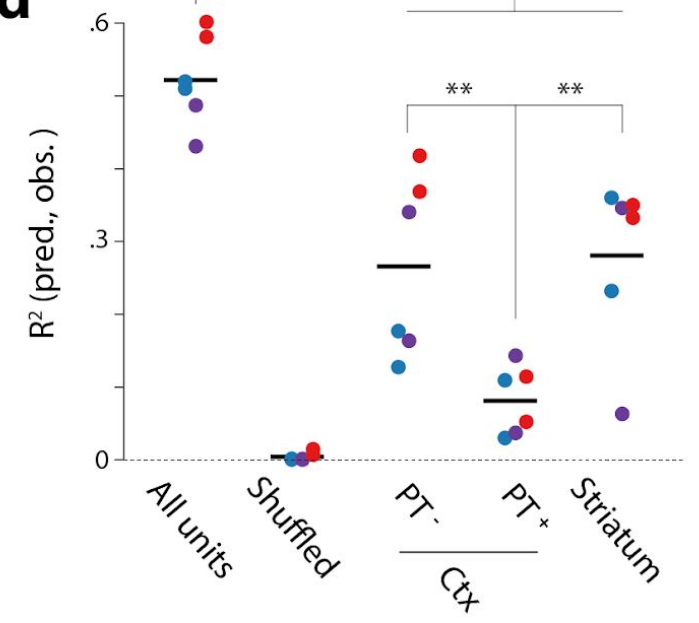

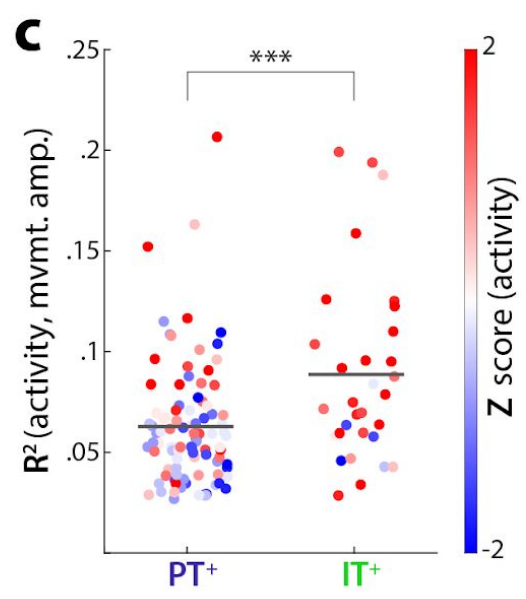

Movement-related modulation (z-score)

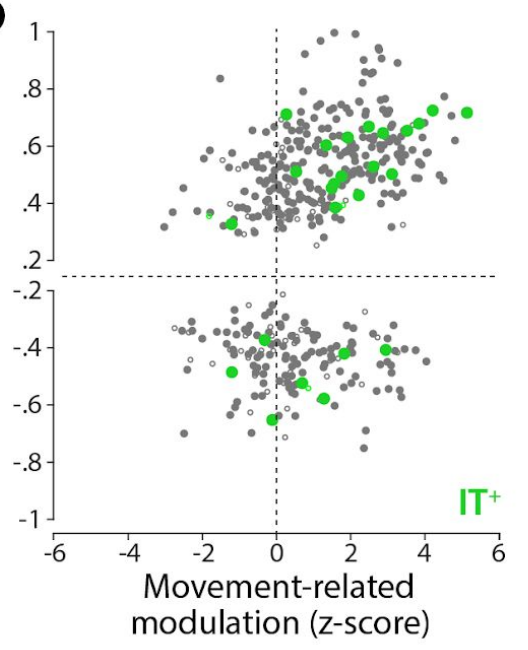

$\mathbf{e}$

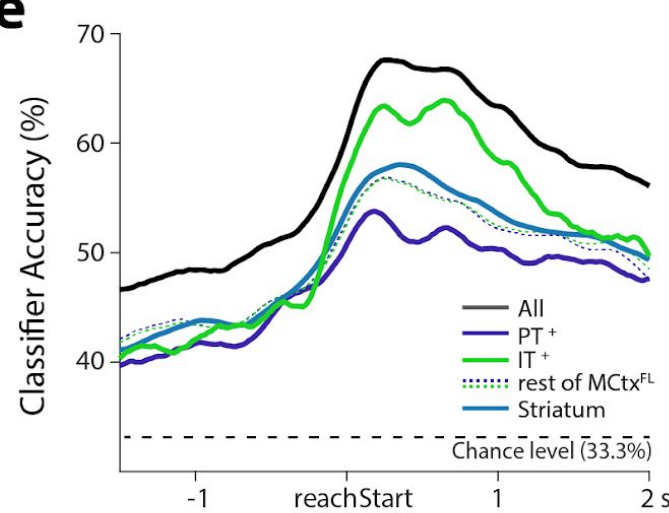

Figure 5 
bioRxiv preprint doi: https://doi.org/10.1101/772517; this version posted February 22, 2021. The copyright holder for this preprint (which was not certified by peer review) is the author/funder, who has granted bioRxiv a license to display the preprint in perpetuity. It is made available under aCC-BY-NC-ND 4.0 International license.

a Variable amplitude joystick task
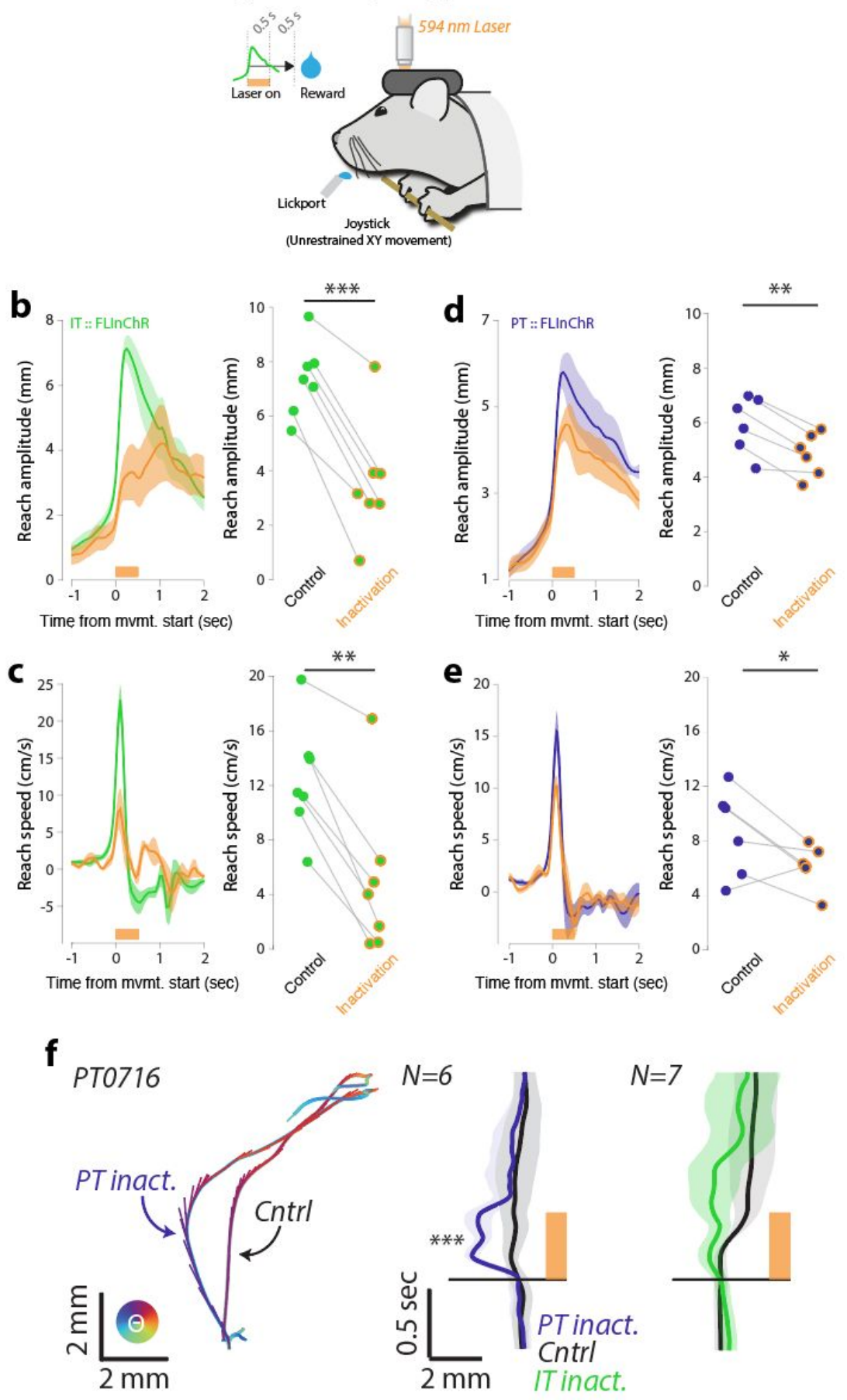

Figure 6 
bioRxiv preprint doi: https://doi.org/10.1101/772517; this version posted February 22, 2021. The copyright holder for this preprint (which was not certified by peer review) is the author/funder, who has granted bioRxiv a license to display the preprint in perpetuity. It is made available under aCC-BY-NC-ND 4.0 International license.

a

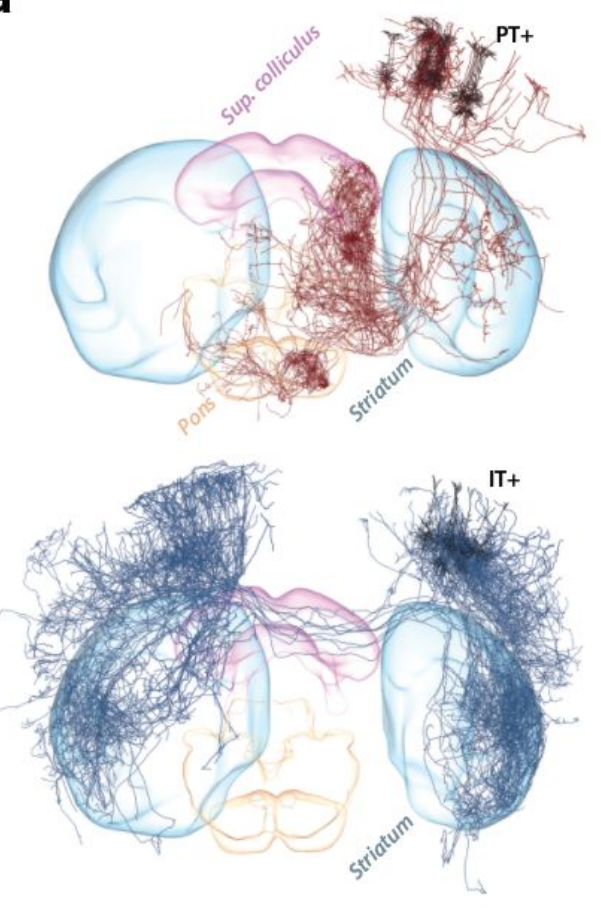

b

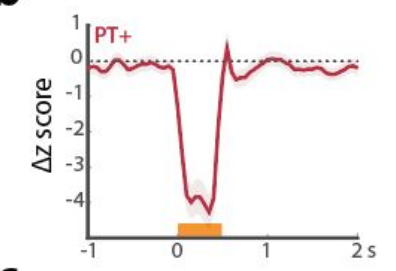

C

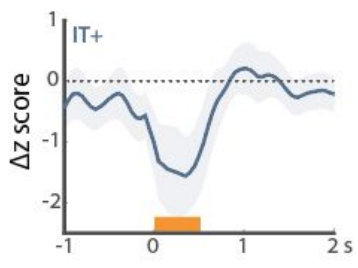

f

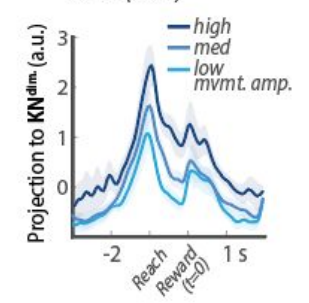

g d

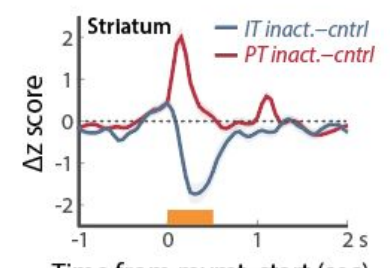

Time from mvmt. start (sec)

e
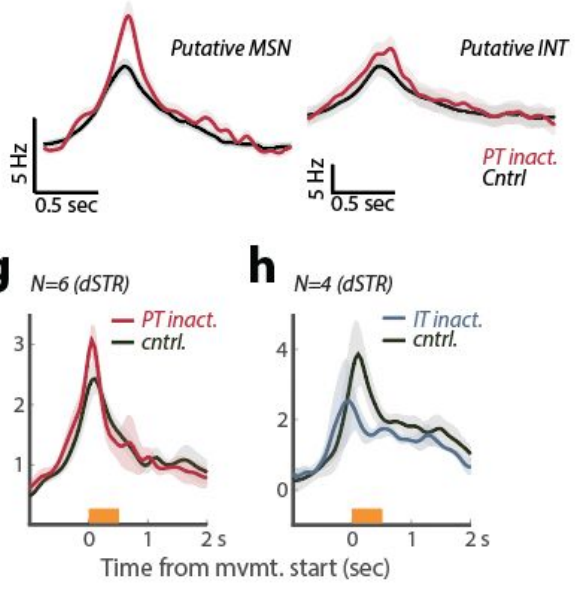

h

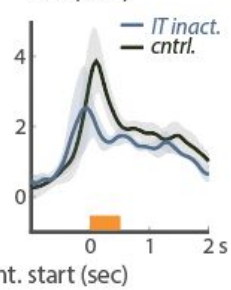

Figure 7 
bioRxiv preprint doi: https://doi.org/10.1101/772517; this version posted February 22, 2021. The copyright holder for this preprint (which was not certified by peer review) is the author/funder, who has granted bioRxiv a license to display the preprint in perpetuity. It is made available under aCC-BY-NC-ND 4.0 International license.

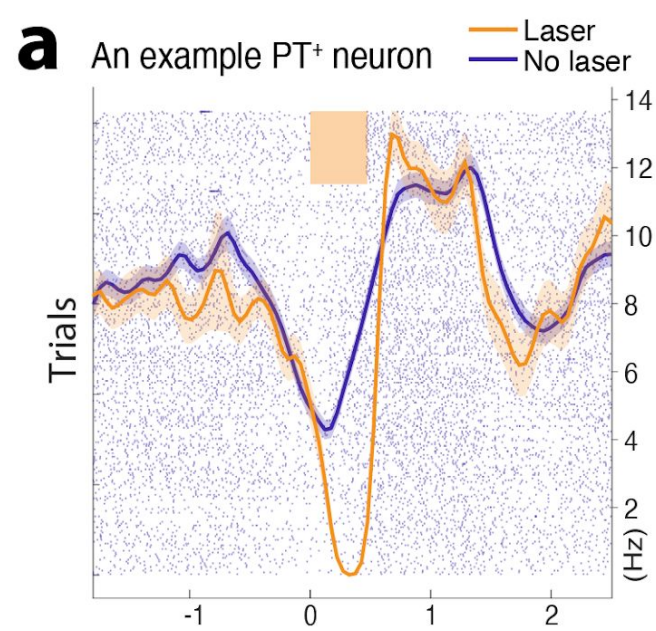

Time from mvmt. start (sec)

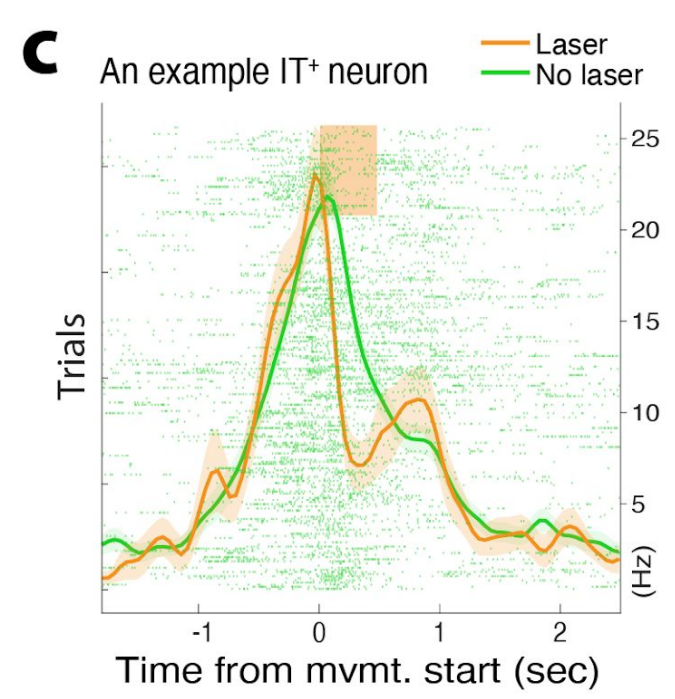

Figure 7-figure supplement 1 b. mvmt.-timed activity in PT silencing

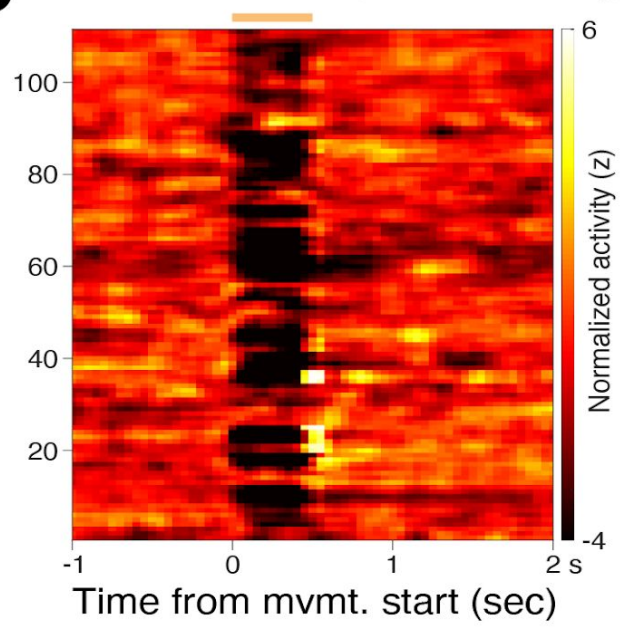

d

$\Delta$ mvmt.-timed activity in IT silencing

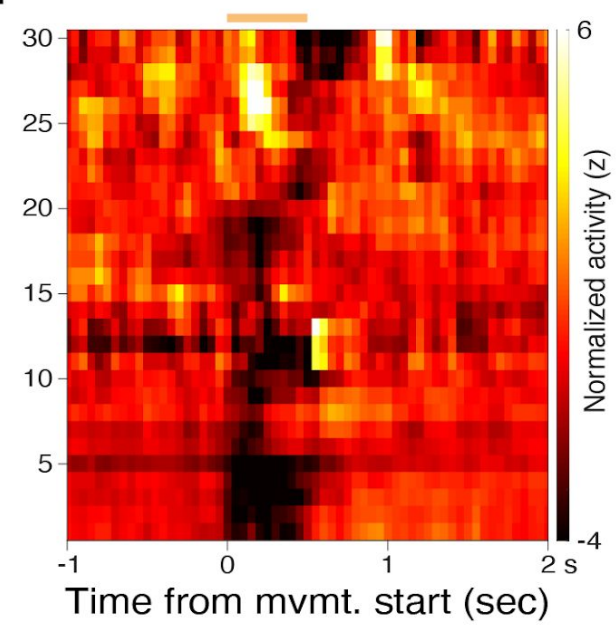

